\title{
CONSIDERATIONS OF THE SCALE OF RADIOCARBON OFFSETS IN THE EAST MEDITERRANEAN, AND CONSIDERING A CASE FOR THE LATEST (MOST RECENT) LIKELY DATE FOR THE SANTORINI ERUPTION
}

\author{
Sturt W Manning \\ Department of Classics and Cornell Tree Ring Laboratory, B48 Goldwin Smith Hall, Cornell University, Ithaca, New York \\ 14853-3201, USA. Corresponding author. Email: sm456@cornell.edu.
}

\section{Bernd Kromer}

Heidelberg Academy of Sciences, c/o Institut für Umweltphysik der Universität Heidelberg, Im Neuenheimer Feld 229, D69120 Heidelberg, and Klaus-Tschira Scientific Dating Laboratory, Curt-Engelhorn-Centre for Archaeometry, Mannheim 68159 , Germany.

\begin{abstract}
The debate over the dating of the Santorini (Thera) volcanic eruption has seen sustained efforts to criticize or challenge the radiocarbon dating of this time horizon. We consider some of the relevant areas of possible movement in the ${ }^{14} \mathrm{C}$ dating-and, in particular, any plausible mechanisms to support as late (most recent) a date as possible. First, we report and analyze data investigating the scale of apparent possible ${ }^{14} \mathrm{C}$ offsets (growing season related) in the Aegean-Anatolia-east Mediterranean region (excluding the southern Levant and especially pre-modern, pre-dam Egypt, which is a distinct case), and find no evidence for more than very small possible offsets from several cases. This topic is thus not an explanation for current differences in dating in the Aegean and at best provides only a few years of latitude. Second, we consider some aspects of the accuracy and precision of ${ }^{14} \mathrm{C}$ dating with respect to the Santorini case. While the existing data appear robust, we nonetheless speculate that examination of the frequency distribution of the ${ }^{14} \mathrm{C}$ data on short-lived samples from the volcanic destruction level at Akrotiri on Santorini (Thera) may indicate that the average value of the overall data sets is not necessarily the most appropriate ${ }^{14} \mathrm{C}$ age to use for dating this time horizon. We note the recent paper of Soter (2011), which suggests that in such a volcanic context some (small) age increment may be possible from diffuse $\mathrm{CO}_{2}$ emissions (the effect is hypothetical at this stage and has not been observed in the field), and that "if short-lived samples from the same stratigraphic horizon yield a wide range of ${ }^{14} \mathrm{C}$ ages, the lower values may be the least altered by old $\mathrm{CO}_{2}$." In this context, it might be argued that a substantive "low" grouping of ${ }^{14} \mathrm{C}$ ages observable within the overall ${ }^{14} \mathrm{C}$ data sets on short-lived samples from the Thera volcanic destruction level centered about $3326-3328 \mathrm{BP}$ is perhaps more representative of the contemporary atmospheric ${ }^{14} \mathrm{C}$ age (without any volcanic $\mathrm{CO}_{2}$ contamination). This is a subjective argument (since, in statistical terms, the existing studies using the weighted average remain valid) that looks to support as late a date as reasonable from the ${ }^{14} \mathrm{C}$ data. The impact of employing this revised ${ }^{14} \mathrm{C}$ age is discussed. In general, a late 17 th century $\mathrm{BC}$ date range is found (to remain) to be most likely even if such a late-dating strategy is followed-a late 17 th century $\mathrm{BC}$ date range is thus a robust finding from the ${ }^{14} \mathrm{C}$ evidence even allowing for various possible variation factors. However, the possibility of a mid-16th century BC date (within $\sim 1593-$ $1530 \mathrm{cal} \mathrm{BC}$ ) is increased when compared against previous analyses if the Santorini data are considered in isolation.
\end{abstract}

\section{INTRODUCTION}

For several decades, there has been a vigorous debate concerning a "low" versus "high" date for the Santorini (Thera) volcanic eruption in the Aegean in the mid-2nd millennium BC (e.g. Hardy and Renfrew 1990; Warburton 2009; Manning 2010). One group of scholars seeks to maintain a traditional, pre-radiocarbon, "low" date range-based on an assessment of the archaeological and arthistorical associations between the Aegean, east Mediterranean, and Egypt-somewhere about 1530-1500 BC or even a little later (e.g. Warren 1984, 1985, 1987, 2009, 2010; Warren and Hankey 1989; Bietak 2003; Wiener 2006, 2009a,b, 2010; Bietak and Höflmayer 2007; MacGillivray 2009). Whereas, another group of scholars observes that the ${ }^{14} \mathrm{C}$ data associated with the Santorini eruption indicate an earlier or "high" date for the eruption in the later 17th century $\mathrm{BC}$, and argue that the archaeological and other evidence can also be so reinterpreted (e.g. Betancourt 1987; Manning 1988, 1999, 2007, 2009; Bronk Ramsey et al. 2004; Friedrich et al. 2006; Manning et al. 2006; Heinemeier et al. 2009; Manning and Bronk Ramsey 2009; Manning and Kromer 2011a). In the last decade, this debate has seen sustained efforts to question the ${ }^{14} \mathrm{C}$ dating related to the Santorini eruption by some critics of the "high" chronology and/or advocates of the "low" chronology, with sug-

(C) 2012 by the Arizona Board of Regents on behalf of the University of Arizona Proceedings of the 6th International Radiocarbon and Archaeology Symposium, edited by E Boaretto and N R Rebollo Franco RADIOCARBON, Vol 54, Nr 3-4, 2012, p 449-474 
gestions that one or more factors somehow affected or biased the ${ }^{14} \mathrm{C}$ dates obtained for this time horizon from the Aegean region or even from the entire east Mediterranean (e.g. Keenan 2002; Bietak 2003; Bietak and Höflmayer 2007; Wiener 2003, 2009a,b, 2010).

Claims for large and systematic errors or offsets for ${ }^{14} \mathrm{C}$ dates relevant to the $3 \mathrm{rd}$, 2nd, or 1st millennia BC east Mediterranean are untenable or incorrectly based (e.g. Manning et al. 2002, 2010; Dee et al. 2009; Manning and Kromer 2011b), and recent work has instead demonstrated a very good correlation between sophisticated ${ }^{14} \mathrm{C}$ dating and standard historical Egyptian chronology through the 2nd millennium BC (Bronk Ramsey et al. 2010; Manning et al. 2012). This does not mean that 2nd millennium BC Egyptian chronology is entirely resolved-indeed there remain several areas for minor debate (e.g. Huber 2011) - but use of the accepted regnal order for the Middle and New Kingdoms, and consideration of 2 mainstream estimates of reign lengths covering a standard higher option and a lower option, integrated with a large ${ }^{14} \mathrm{C}$ database and a sophisticated analytical framework, leads to a coherent model (data versus known history of atmospheric ${ }^{14} \mathrm{C}$ levels), and so a timeframe requiring an Egyptian chronology more or less in the range of the standard historically based estimates (Bronk Ramsey et al. 2010). ${ }^{1}$

With regard to ${ }^{14} \mathrm{C}$ offsets, the important discovery in the course of the Oxford Project on Radiocarbon Dating and the Egyptian Historical Chronology is the evidence for an apparent and small $\sim 19 \pm$ $5{ }^{14} \mathrm{C}$ yr offset relevant to pre-modern, pre-Aswan dam samples growing in Egypt (Dee et al. 2010). This offset, related to the pre-dam hydrological cycle in Egypt that placed the Nile Valley growing season almost at the opposite to the standard Northern Hemisphere spring-summer growing period, offers more or less a maximum possible growing-season-related offset for the mid to lower (nontropics) latitudes of the Northern Hemisphere. It logically does not apply elsewhere in the east Mediterranean (excluding the southern Levant, where there is more of an offset in growing seasons, and so there may be more of a ${ }^{14} \mathrm{C}$ offset; this is a topic that needs a separate investigation: project in progress), where the typical main growing season is spring to summer and at most only slightly offset from the standard mid-latitude Northern Hemisphere growing season as represented by the trees used for constructing the Northern Hemisphere ${ }^{14} \mathrm{C}$ calibration curve (Reimer et al. 2009). Extending previous work (Manning et al. 2010), we investigate in this paper data from tree rings relevant to the likely scale of a possible growing-season-related offset for other areas of the Aegean and east Mediterranean for spring to summer growth to investigate the existence and scale of any apparent offsets, and then consider the possible relevance of such offsets to the Santorini case.

\footnotetext{
${ }^{1}$ Huber (2011:211) accepts that the Bronk Ramsey et al. (2010) study rules out some revisionist low chronologies and questions other extreme views, and he refers to the Bronk Ramsey date ranges in various places, but generally Huber expresses some caution since he sees greater flexibility in some reign lengths than he believes allowed for, and incorrectly states (p 209) that "they [Bronk Ramsey et al.] do not provide details about the sophisticated program used by them to analyze the radiocarbon data." This reflects Huber's lack of knowledge regarding this topic: the OxCal software and the Bayesian approach employed has of course been the subject of extensive publications including a number in Radiocarbon and Huber (or anyone else) can run the Egyptian models of Bronk Ramsey et al. (2010) and try slightly different reign length adjustments according to taste given both the full OxCal runfile code provided in the Supporting Online Material of Bronk Ramsey et al. (http://www.sciencemag.org/content/suppl/2010/06/15/328.5985.1554.DC1/Bronk_Ramsey.SOM.revision.1.pdf) and the open availability of $\mathrm{OxCal}$ at http://cl4.arch.ox.ac.uk/ (where development history and extensive bibliography are also available). In particular, Bronk Ramsey et al. (2010) in the Supporting Online Material show that their findings are fairly robust, even if reign length uncertainties are increased by a factor of 2, or if the alternative reign lengths of Hornung et al. (2006) are employed, or if the default prior outlier probability (and so uncertainty allowed for) is increased: Figures S2, S3, and S4. Most of the likely variations in mainstream scholarly opinion thus lie within the range of one or other of the models Bronk Ramsey et al. (2010) present, and so are approximately allowed for.
} 
For the specific case of the dating of the Santorini eruption (and associated contexts), there have been claims that the ${ }^{14} \mathrm{C}$ data somehow are not representative of the contemporary (mid-latitude Northern Hemisphere) real ${ }^{14} \mathrm{C}$ age. We review the published data and find it is generally robust (see also Manning and Kromer 2011a). However, we note the recent paper by Soter (2011), which "suggests that plants growing in tectonically active areas can assimilate old carbon from the diffuse emission of old $\mathrm{CO}_{2}$, either by root uptake in the soil or by photosynthesis in the canopy. Such assimilation may be sufficient to produce detectable ${ }^{14} \mathrm{C}$ age increments, but it remains to demonstrate whether it actually occurs in the field" ( $p$ 66). The Santorini case is clearly implied as a possible instance. The important difference in Soter's discussion of the topic, compared to the previous literature, is that he offers a case for the existence of relatively minor age increments. Previous discussions concerned the typically large and time-varying offsets observed when plant matter grows close to a source of volcanic $\mathrm{CO}_{2}$. Most workers had concluded that such gross and typically highly variable effects did not appear evident in the majority of the Santorini ${ }^{14} \mathrm{C}$ samples relevant to the time of the eruption (i.e. in data obtained on short-lived plant matter from the final volcanic destruction level), since the majority of the data offered relatively similar ages (Friedrich et al. 1990; Heinemeier et al. 2009:288; Manning et al. 2009:300-4).

However, Soter's suggestion of mechanisms allowing for the possibility of the relevance of a much smaller age increment is a key issue, and returns us very much to the debate at the Third Thera Conference of 1989 between the groups from Simon Fraser University and Oxford University over a claimed, or supposed, relatively minor older age contaminant fraction-or not—in short-lived samples from the volcanic destruction level at Akrotiri, Thera (Housley et al. 1990; Nelson et al. 1990; Manning 1999:232-47).

In areas potentially affected by a diffuse flux of volcanic $\mathrm{CO}_{2}$, Soter concludes by suggesting that "if short-lived samples from the same stratigraphic horizon yield a wide range of ${ }^{14} \mathrm{C}$ ages, the lower values may be the least altered by old $\mathrm{CO}_{2}$ " ( $\mathrm{p}$ 66). In light of Soter's paper, we re-examine the available ${ }^{14} \mathrm{C}$ data on short-lived samples from the volcanic destruction level on Thera. While noting Soter's caveat that it "remains to demonstrate whether it [a detectable ${ }^{14} \mathrm{C}$ age increment] actually occurs in the field" ( $p$ 66), it is suggested here, by looking at the frequency distributions of the data sets available, that there may (subjective assessment) in fact be evidence of small ${ }^{14} \mathrm{C}$ age increments affecting some data, and that there is a potentially important substantive set (or clump) of "lower values" that may perhaps be argued to offer a better ${ }^{14} \mathrm{C}$ age estimate for the volcanic destruction level on Thera-in contrast to the overall set average value (if one wishes to make this subjective argument-i.e. we pursue an even if approach). The impact of employing both this potentially more relevant revised ${ }^{14} \mathrm{C}$ age estimate, and the likely possible growing-season-related offset factor, are considered in terms of setting the very latest plausible date for the Santorini eruption and the associated archaeological horizon on the basis of ${ }^{14} \mathrm{C}$ dating.

\section{METHODS}

To investigate the scale of possible growing-season-related ${ }^{14} \mathrm{C}$ offsets relevant to the Aegean-Anatolian-east Mediterranean region (excluding the southern Levant and Egypt), we consider some ${ }^{14} \mathrm{C}$ time series obtained from tree rings — either of known age or near-absolutely placed-available from the east Mediterranean (see some previous analyses reported in Manning et al. 2010). All the data employed in the analyses considered in this paper were run at the Heidelberg Radiocarbon Laboratory (for laboratory details, see Kromer et al. 2010:875). Thus, to begin, we considered the accuracy of 2 sets of Heidelberg Laboratory measurements on known-age German oak versus the IntCal09 data set (Reimer et al. 2009) to demonstrate the good agreement of the Heidelberg measurements 
against IntCal09. The German oak came from the Hohenheim dendrochronology (Friedrich et al. 2004) with the ${ }^{14} \mathrm{C}$ data employed for the AD period listed in Table 1 , and the data for the $\mathrm{BC}$ period taken from Kromer et al. (2010). We then investigated differences between several time series from east Mediterranean tree-ring samples against the current standard Northern Hemisphere ${ }^{14} \mathrm{C}$ calibration data set of IntCal09 (Reimer et al. 2009). The $\Delta \mathrm{R}$ function in the OxCal software (Bronk Ramsey 2009b) was employed for these analyses and to produce the plots illustrated. An offset test of $0 \pm$ $20{ }^{14} \mathrm{C}$ yr was employed except in one case (see below) and a curve resolution of 1 .

Reconsideration of the ${ }^{14} \mathrm{C}$ dating of Santorini is based on existing published data on short-lived samples relevant to the volcanic destruction level at Akrotiri (Friedrich et al. 2006; Manning et al. 2006; Manning 2009; Manning and Bronk Ramsey 2009). ${ }^{14} \mathrm{C}$ analysis (modeling) employs OxCal (Bronk Ramsey 1995, 2008, 2009a,b) and IntCal09 (Reimer et al. 2009). Several sets of ${ }^{14} \mathrm{C}$ data on shortlived plant material from the Thera volcanic destruction level from the archaeological site of Akrotiri have been published, with the data fully and readily available (shown in Manning and Kromer 2011a: Figure 1). Here, we consider a starting overall set (Set 1) of 43 data, comprising the 28 data employed in the Manning et al. (2006) analysis (see their SOM Table S1) and in addition 12 of the University of Pennsylvania data listed in Manning (1988: Table 4 comprising P-1697, 1885, 1888, 1889, 1892 , $1894,1895,2559,2560,2561,2565,2791)$ and 3 ETH data from Kutschera and Stadler (2000: Table 2 comprising ETH-3315, 3323, 3324); then the more selected (on appropriateness and quality grounds) subset of 28 dates (Set 2) employed by Manning et al. (2006); and in particular a smaller subset of 25 of these dates (Set 3). Frequency plots of distributions of the midpoints of the ${ }^{14} \mathrm{C}$ ages for the 43 and 25 date sets ( 1 and 3 ) are shown in Figures 9-10, the latter divided up by species dated.

\section{RESULTS-RADIOCARBON OFFSETS IN THE AEGEAN AND EAST MEDITERRANEAN (OTHER THAN THE NILE HYDROLOGIC ZONE AND SOUTHERN LEVANT)}

A comparison of Heidelberg Radiocarbon Laboratory measurements on known-age German oak shows that they compare very closely with the IntCal09 calibration curve in both an AD and BC period test: Figures 1-3. Of course, this is partly circular as some of these data are incorporated into

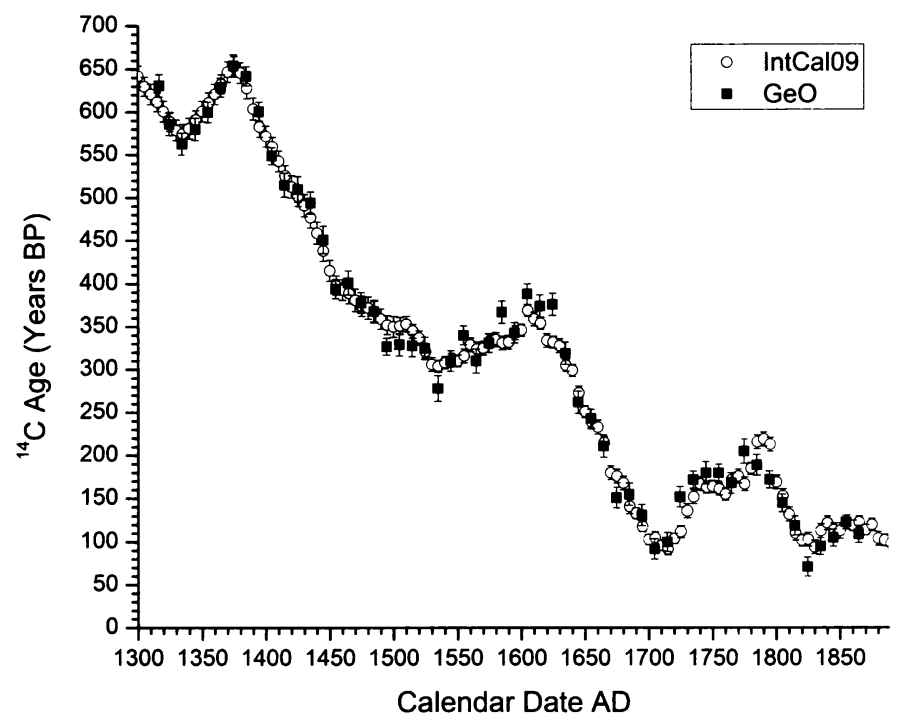

Figure $1{ }^{14} \mathrm{C}$ data measured at the Heidelberg Radiocarbon Laboratory on decadal sections of known-age German oak $(\mathrm{GeO})$ from the Hohenheim dendrochronology (Friedrich et al. 2004) for the period between AD 1314-1869 $(n=56)$ plotted against the IntCal09 calibration curve (Reimer et al. 2009), $1 \sigma$ errors shown. GeO data shown are listed in Table 1. 
the calibration data set, but in the $\mathrm{AD}$ period there are many more data from other sources and yet there is a very close comparison, and in the $\mathrm{BC}$ period the Heidelberg data again agree well with a range of data from other laboratories (see also Kromer et al. 2001: Figure 1; Manning and Kromer 2011a: Figures 3-4). Regardless of circularity, the outcome is that we can assert that Heidelberg Radiocarbon Laboratory measurements compare very closely to the IntCal09 calibration curve. In turn, we can therefore regard comparisons of Heidelberg Radiocarbon Laboratory measurements on other data sets against IntCal09 as a good basis (like to like) to assess the reality and extent of any possible ${ }^{14} \mathrm{C}$ offsets.

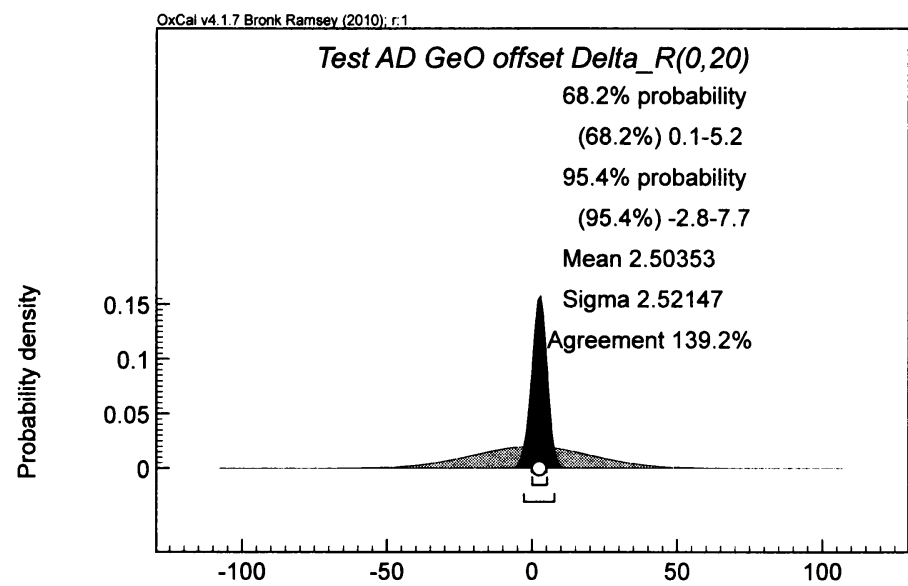

Figure 2 Typical output of a consideration of whether there is a systematic regional offset operating when comparing the known-age AD period German oak $(\mathrm{GeO})$ data (see Figure 1) measured at Heidelberg Radiocarbon Laboratory against IntCal09 (Reimer et al. 2009) with curve resolution set at 1 employing the $\Delta \mathrm{R}$ function in OxCal with a prior of $0 \pm 20 \mathrm{yr}$ (Bronk Ramsey 1995, 2009a,b; Bronk Ramsey et al. 2001). (Note: bibliographic references for IntCal and OxCal are not repeated in subsequent captions.) The Heidelberg GeO data are for samples centered AD 1316.5 to 1864.5. The analysis finds a tiny (negligible) ${ }^{14} \mathrm{C}$ offset $(\Delta \mathrm{R})$ of (expressed as the $\mu \pm \sigma$ ) of $2.5 \pm 2.5{ }^{14} \mathrm{C} \mathrm{yr}$. The wiggle-match fit places the known-age time series very close to its known date. Thus, the first sample is centered at AD 1316.5 versus a modeled fit with $\mu \pm \sigma$ of $\mathrm{AD} 1318 \pm 2$ and against $68.2 \%$ and $95.4 \%$ probability ranges of, respectively, AD 1316-1320 and 1315-1320 (note: no cleaning of the sequence for outliers has been undertaken).

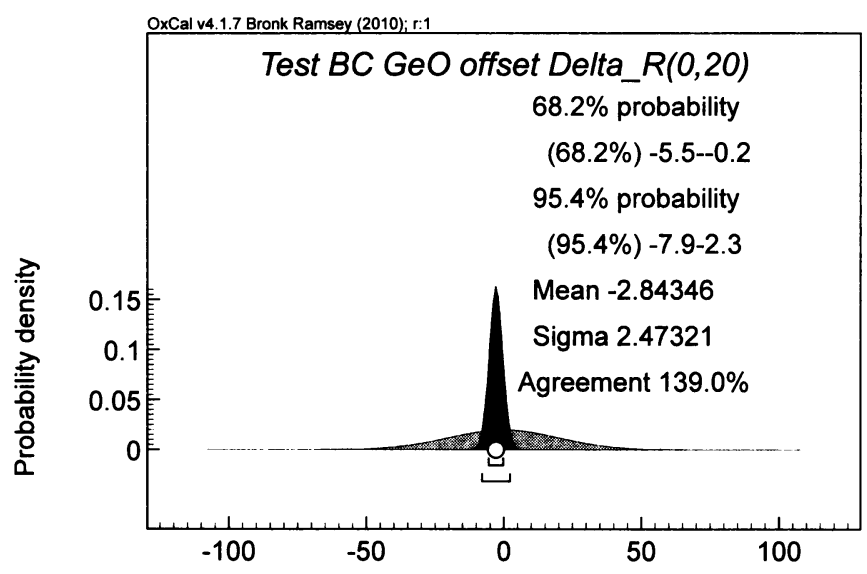

Figure 3 Typical output of a consideration of whether there is a systematic regional offset operating when comparing known-age German oak $(\mathrm{GeO})$ data covering 1730-1480 BC measured at the Heidelberg Radiocarbon Laboratory (Kromer et al. 2010) against IntCal09 with curve resolution set at 1 employing the $\Delta \mathrm{R}$ function in $\mathrm{OxCal}$ with a prior of $0 \pm 20 \mathrm{yr}$. The Heidelberg $\mathrm{GeO}$ data are for samples centered 1735 to $1482 \mathrm{BC}$. The analysis finds a tiny (negligible) ${ }^{14} \mathrm{C}$ offset $(\Delta R)$ of (expressed as the $\mu \pm \sigma)-2.8 \pm 2.5{ }^{14} \mathrm{C}$ yr. The wigglematch fit places the known-age time series extremely close to its known date. Thus, the first sample is centered at $1735 \mathrm{BC}$ versus a modeled fit with $\mu \pm \sigma$ of $1736 \pm 1 \mathrm{BC}$ and against $68.2 \%$ and $95.4 \%$ probability ranges of, respectively, 1737-1735 and 1739-1733 $\mathrm{BC}$ (note: no cleaning of the sequence for outliers has been undertaken). 
Table 1 Heidelberg ${ }^{14} \mathrm{C}$ ages for known-age $\mathrm{AD}$ period samples of German oak from the Hohenheim dendrochronology run as part of the East Mediterranean Radiocarbon (Inter-) Comparison Project (EMRCP) (some illustrated in Kromer et al. 2001; Manning et al. 2006; and data incorporated into the IntCal database). Tree-ring samples kindly provided by Michael Friedrich.

\begin{tabular}{|c|c|c|c|c|c|}
\hline Center ring & Start ring & End ring & ${ }^{14} \mathrm{C}$ age (yr BP) & SD & Hd code \\
\hline 1316.5 & 1314 & 1319 & 631 & 13 & 23116 \\
\hline 1324.5 & 1320 & 1329 & 586 & 13 & 23117 \\
\hline 1334.5 & 1330 & 1339 & 563 & 13 & 23118 \\
\hline 1344.5 & 1340 & 1349 & 580 & 13 & 23124 \\
\hline 1354.5 & 1350 & 1359 & 600 & 12 & 23125 \\
\hline 1364.5 & 1360 & 1369 & 629 & 11 & 23255 \\
\hline 1374.5 & 1370 & 1379 & 654 & 13 & 23126 \\
\hline 1384.5 & 1380 & 1389 & 642 & 11 & 23035 \\
\hline 1394.5 & 1390 & 1399 & 601 & 11 & 23036 \\
\hline 1404.5 & 1400 & 1409 & 549 & 10 & 23039 \\
\hline 1414.5 & 1410 & 1419 & 515 & 14 & 23119 \\
\hline 1425 & 1420 & 1429 & 510 & 15 & 19940 \\
\hline 1435 & 1430 & 1439 & 494 & 13 & 19950 \\
\hline 1445 & 1440 & 1449 & 451 & 16 & 19949 \\
\hline 1454.5 & 1450 & 1459 & 394 & 11 & 19477 \\
\hline 1464.5 & 1460 & 1469 & 401 & 14 & 19485 \\
\hline 1474.5 & 1470 & 1479 & 378 & 12 & 19484 \\
\hline 1484.5 & 1480 & 1489 & 368 & 13 & 19478 \\
\hline 1494.5 & 1490 & 1499 & 327 & 10 & 19390 \\
\hline 1504.5 & 1500 & 1509 & 329 & 13 & 19440 \\
\hline 1514.5 & 1510 & 1519 & 328 & 13 & 19439 \\
\hline 1524.5 & 1520 & 1529 & 325 & 13 & 19442 \\
\hline 1534.5 & 1530 & 1539 & 278 & 15 & 19816 \\
\hline 1544.5 & 1540 & 1549 & 310 & 12 & 19509 \\
\hline 1554.5 & 1550 & 1559 & 340 & 11 & 19510 \\
\hline 1564.5 & 1560 & 1569 & 310 & 14 & 19815 \\
\hline 1574.5 & 1570 & 1579 & 331 & 11 & 19539 \\
\hline 1584.5 & 1580 & 1589 & 367 & 13 & 19817 \\
\hline 1594.5 & 1590 & 1599 & 343 & 12 & 19548 \\
\hline 1604.5 & 1600 & 1609 & 388 & 12 & 19705 \\
\hline 1614.5 & 1610 & 1619 & 374 & 13 & 19706 \\
\hline 1624.5 & 1620 & 1629 & 376 & 13 & 19737 \\
\hline 1634.5 & 1630 & 1639 & 319 & 13 & 19755 \\
\hline 1644.5 & 1640 & 1649 & 262 & 13 & 19756 \\
\hline 1654.5 & 1650 & 1659 & 243 & 11 & 23056 \\
\hline 1664.5 & 1660 & 1669 & 211 & 13 & 23057 \\
\hline 1674.5 & 1670 & 1679 & 151 & 12 & 23055 \\
\hline 1684.5 & 1680 & 1689 & 155 & 13 & 23059 \\
\hline 1694.5 & 1690 & 1699 & 131 & 12 & 23073 \\
\hline 1704.5 & 1700 & 1709 & 92 & 12 & 23072 \\
\hline 1714.5 & 1710 & 1719 & 100 & 11 & 23051 \\
\hline 1724.5 & 1720 & 1729 & 152 & 12 & 23048 \\
\hline 1734.5 & 1730 & 1739 & 172 & 10 & 23047 \\
\hline 1744.5 & 1740 & 1749 & 180 & 13 & 23061 \\
\hline 1754.5 & 1750 & 1759 & 180 & 10 & 23053 \\
\hline 1764.5 & 1760 & 1769 & 168 & 12 & 23054 \\
\hline
\end{tabular}


Table 1 Heidelberg ${ }^{14} \mathrm{C}$ ages for known-age AD period samples of German oak from the Hohenheim dendrochronology run as part of the East Mediterranean Radiocarbon (Inter-) Comparison Project (EMRCP) (some illustrated in Kromer et al. 2001; Manning et al. 2006; and data incorporated into the IntCal database). Tree-ring samples kindly provided by Michael Friedrich. (Continued)

\begin{tabular}{llllll}
\hline Center ring & Start ring & End ring & ${ }^{14} \mathrm{C}$ age $(\mathrm{yr}$ BP $)$ & SD & Hd code \\
\hline 1774.5 & 1770 & 1779 & 205 & 14 & 23062 \\
1784.5 & 1780 & 1789 & 189 & 12 & 22883 \\
1794.5 & 1790 & 1799 & 172 & 10 & 22884 \\
1804.5 & 1800 & 1809 & 145 & 10 & 22885 \\
1814.5 & 1810 & 1819 & 119 & 11 & 22886 \\
1824.5 & 1820 & 1829 & 71 & 11 & 22888 \\
1834.5 & 1830 & 1839 & 95 & 10 & 22889 \\
1844.5 & 1840 & 1849 & 105 & 10 & 22890 \\
1854.5 & 1850 & 1859 & 123 & 8 & 22925 \\
1864.5 & 1860 & 1869 & 109 & 10 & 22891 \\
\hline
\end{tabular}

Figures 4-8 show several comparisons of Heidelberg Radiocarbon Laboratory measurements on times series from tree-ring samples from the Aegean-Anatolia-east Mediterranean region. These form a more or less north to south and west to east transect covering in all in approximate rounded terms $40^{\circ}$ to $34^{\circ} \mathrm{N}$ and $27^{\circ}$ to $34^{\circ} \mathrm{E}$ and so much of the eastern Aegean, Anatolia, and the east Mediterranean (excluding the southern Levant). The first comparison, on known-age pine from northwestern Turkey over a 500-yr period from AD 1300-1800 (Figure 4), shows very little or negligible apparent offset, with a $\mu \pm \sigma$, of just $\sim 1.2 \pm 2.3{ }^{14} \mathrm{C}$ yr. The second comparison, on the older part of the time series from juniper from Gordion covering $378 \mathrm{yr}$ (tree rings) with $44{ }^{14} \mathrm{C}$ data in the mid2nd millennium BC, again offers only a very small to negligible apparent offset, with a $\mu \pm \sigma$, of just $\sim 3.6 \pm 6.2{ }^{14} \mathrm{C}$ yr: Figure 5. (There is an apparent offset more on the decadal scale when looking at the more recent part of the Gordion time series-see discussions in Manning et al. 2010-but this reflects specific issues - especially the major solar minimum in the later 9th to mid-8th centuries $\mathrm{BC}$, but also some apparent need for revision to IntCal09 in the 14th-13th centuries BC - and so it is not appropriate for typical periods and situations in the Aegean and east Mediterranean.)

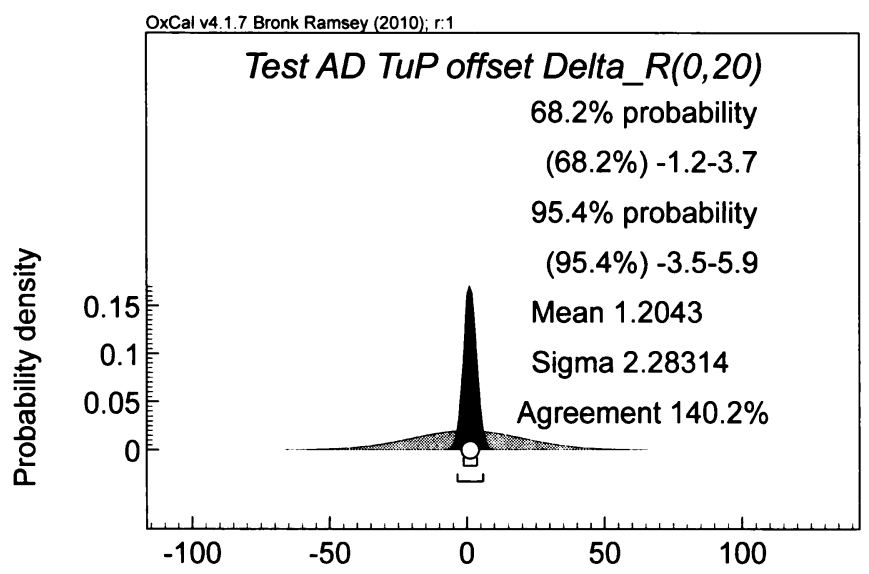

Figure 4 Typical output of a consideration of whether there is a systematic regional offset operating when comparing a time series of ${ }^{14} \mathrm{C}$ data $(n=52)$ from a known-age Turkish pine tree-ring chronology from NW Turkey between AD 1300-1800 against IntCal09 with curve resolution set at 1 employing the $\Delta \mathrm{R}$ function in $\mathrm{OxCal}$ with a prior of $0 \pm 20 \mathrm{yr}$. The ${ }^{14} \mathrm{C}$ data are listed in Manning et al. (2010: Table 7) and shown in Manning et al. (2010: Figure 13 Upper). Only a very small apparent offset, citing $\mu \pm \sigma$, of $1.2 \pm 2.3{ }^{14} \mathrm{C}$ yr is found for the overall set (compare with Manning et al. 2010: Figure 13 Lower where curve resolution 5 was employed). 


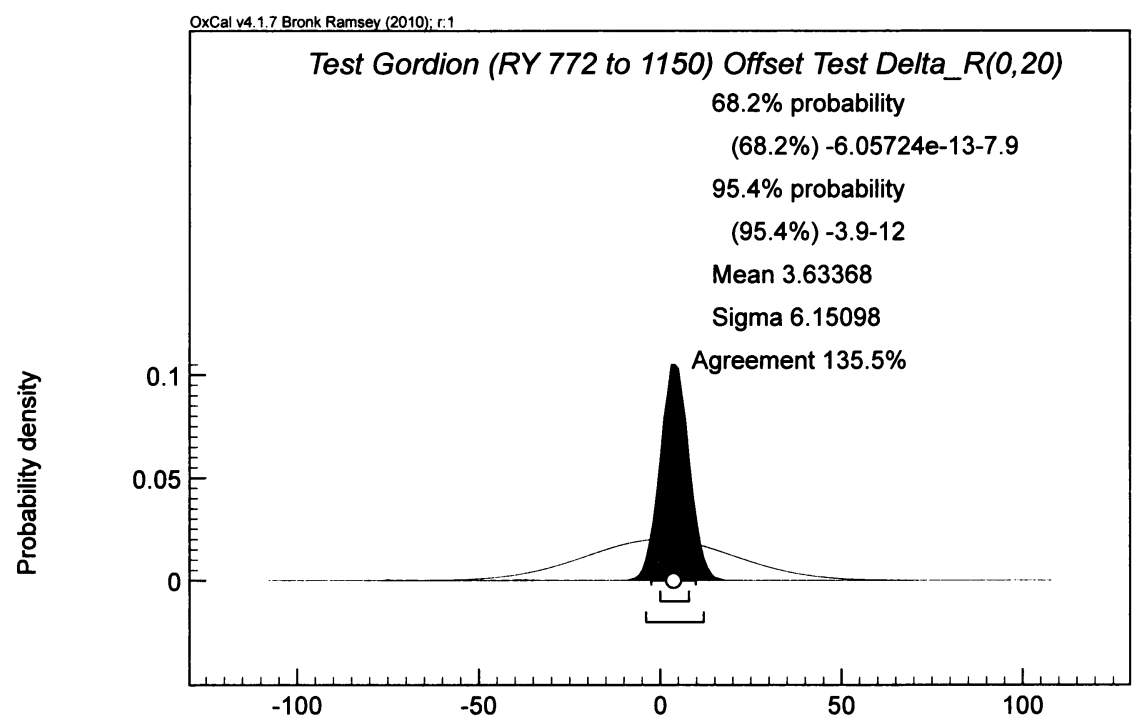

Figure 5 Typical output of a consideration of whether there is a systematic regional offset operating when comparing a time series of ${ }^{14} \mathrm{C}$ data $(n=44)$ sequenced at known tree-ring intervals along a dendrochronological time series of 378 rings (years) from Juniper from Gordion, central Anatolia, from the 2nd millennium BC against IntCal09 with curve resolution set at 1 employing the $\Delta \mathrm{R}$ function in $\mathrm{OxCal}$ with a prior of $0 \pm 20 \mathrm{yr}$. The ${ }^{14} \mathrm{C}$ data employed are listed in Manning et al. (2010: Table 4). Only a very small apparent offset, citing $\mu \pm \sigma$, of $\sim 3.6 \pm 6.2{ }^{14} \mathrm{C} \mathrm{yr}$ is found for the overall set (compare with Manning et al. 2010: Figure 7 where curve resolution 5 was employed). The outcome from a typical run is shown; a few runs see slightly larger offsets (to $\sim 5.1 \pm 9.2$ in runs considered for this paper), but in no case is 0 outside the SD range.

The third comparison is for ${ }^{14} \mathrm{C}$ data from a short time series of 7 decades of oak from archaeological excavations at Miletos, western Turkey. The data fit closely to the shape of the calibration curve: Figure 6A. The offset is less constrained for such a small set, and whereas the other comparisons consider an offset test of $0 \pm 20{ }^{14} \mathrm{C}$ yr, we show just $0 \pm 10 \mathrm{yr}$ for the Miletos samples. The apparent offset is again small to negligible (with the SD outweighing any possible small offset found) with $\mu \pm \sigma$ of $\sim 3.8 \pm 8.1{ }^{14} \mathrm{C} \mathrm{yr}$ (if an offset test of $0 \pm 20{ }^{14} \mathrm{C}$ yr is employed then this becomes $5.7 \pm 15.4$ ${ }^{14} \mathrm{C}$ yr): Figure $6 \mathrm{~B}$. The fourth comparison is for $17{ }^{14} \mathrm{C}$ dates on $12 \mathrm{known}$-age decadal samples over 130 calendar yr (AD 1801-1930) from a Pinus brutia chronology from the Stavros tis Psokas area, western Cyprus. One measurement stands out as an outlier (datum for the interval AD 18611870). With this datum excluded, the apparent offset against IntCal09, citing $\mu \pm \sigma$, is about $-1.1 \pm$ $3.4{ }^{14} \mathrm{C} \mathrm{yr}$ (and even with the outlier included it remains small at about $-5.0 \pm 3.3{ }^{14} \mathrm{C} \mathrm{yr}$ ): Figure 7 . The fifth and final comparison reported here is from $6{ }^{14} \mathrm{C}$ dates on 6 known-age samples over 60 calendar yr (AD 1800-1859) from a Cedrus libani chronology from the Bcharre area, Lebanon, against IntCal09. The apparent offset reported is again very small to negligible with $\mu \pm \sigma, \sim 0.7 \pm$ $6.9{ }^{14} \mathrm{C}$ yr. The wiggle-match of the data closely fits the calibration curve in 2 possible places (see Figure $7 \mathrm{~A})$ with the correct known-age fit clearly the most likely $(60.4 \%$ of total probability versus the alternative at $7.8 \%$ probability, taking the most likely $68.2 \%$ range in the example shown and with a 0.1 rounding error-in no runs did the likelihoods go below $57.1 \%$ versus $11.1 \%$ ). 

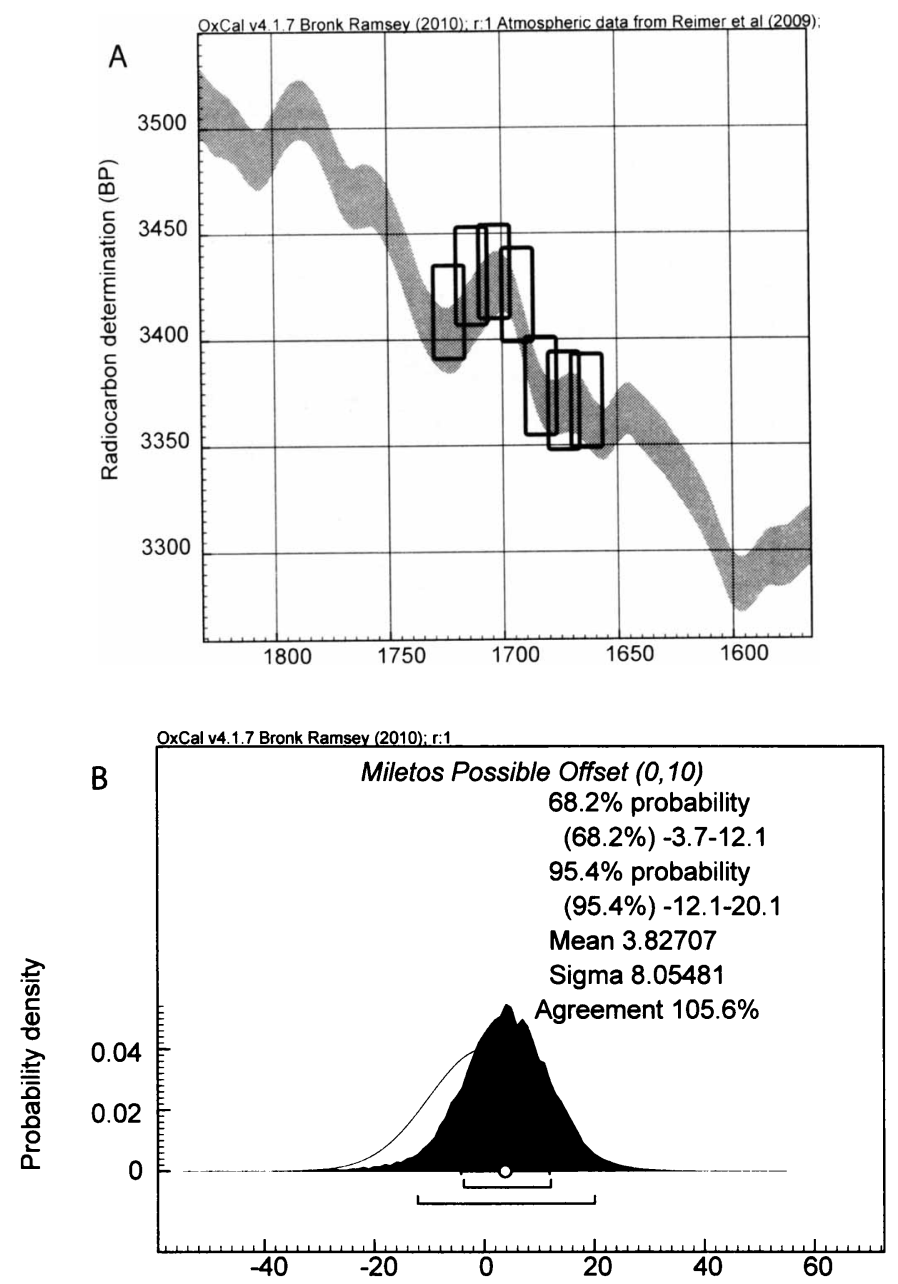

Figure 6 A. Wiggle-match fit against IntCal09 of the weighted average of $2{ }^{14} \mathrm{C}$ measurements on each of seven $11-\mathrm{yr}$ samples from an oak sample from Miletos, western Turkey (Bronk Ramsey et al. 2004; Galimberti et al. 2004; Manning et al. 2006). Boxes show $68.2 \%$ probability ranges. Compare Manning et al. (2010: Figure 11). B. A typical output of a consideration of whether there is a systematic regional offset operating when comparing the Miletos data set against IntCal09 (curve resolution 1) using the $\Delta \mathrm{R}$ function in $\mathrm{OxCal}$ with a prior of $0 \pm 10 \mathrm{yr}$. Only a small to negligible offset is found, $\mu \pm \sigma$ of $\sim 3.8 \pm 8.1{ }^{14} \mathrm{C}$ yr. If a larger prior range is employed, e.g. $0 \pm 20 \mathrm{yr}$ as in the previous examples, then the possible offset range becomes larger (since this is a very small set of data), -4.4 to 19 at $68.2 \%$ probability, but the $\mu \pm \sigma$ remains similar and relatively small to negligible at $\sim 5.7 \pm 15.4{ }^{14} \mathrm{C}$ yr. Compare Manning et al. (2010: Figure 12).

\section{RESULTS-SANTORINI DATA SET AND DATA PATTERN}

The 28-date set (set 2) of ${ }^{14} \mathrm{C}$ measurements on short-lived sample matter from the Akrotiri volcanic destruction level (VDL) employed in the Manning et al. (2006) study passes a chi-squared $\left(\chi^{2}\right)$ test following the Ward and Wilson (1978) approach with a test statistic $(T)=31.5<39.9$ at $5 \%$ level for df27. The weighted average ${ }^{14} \mathrm{C}$ age is $3345 \pm 8 \mathrm{BP}$. This implies that there is no statistically significant indication of a wider scatter of the data than can be randomly expected (and thus any apparent minor bias in the set is by chance, and yet by chance some such bias has to be present and so can be ignored). Indeed, although the overall 43 date set (set 1 ) fails a $\chi^{2}$ test (this set noticeably has 3 data 

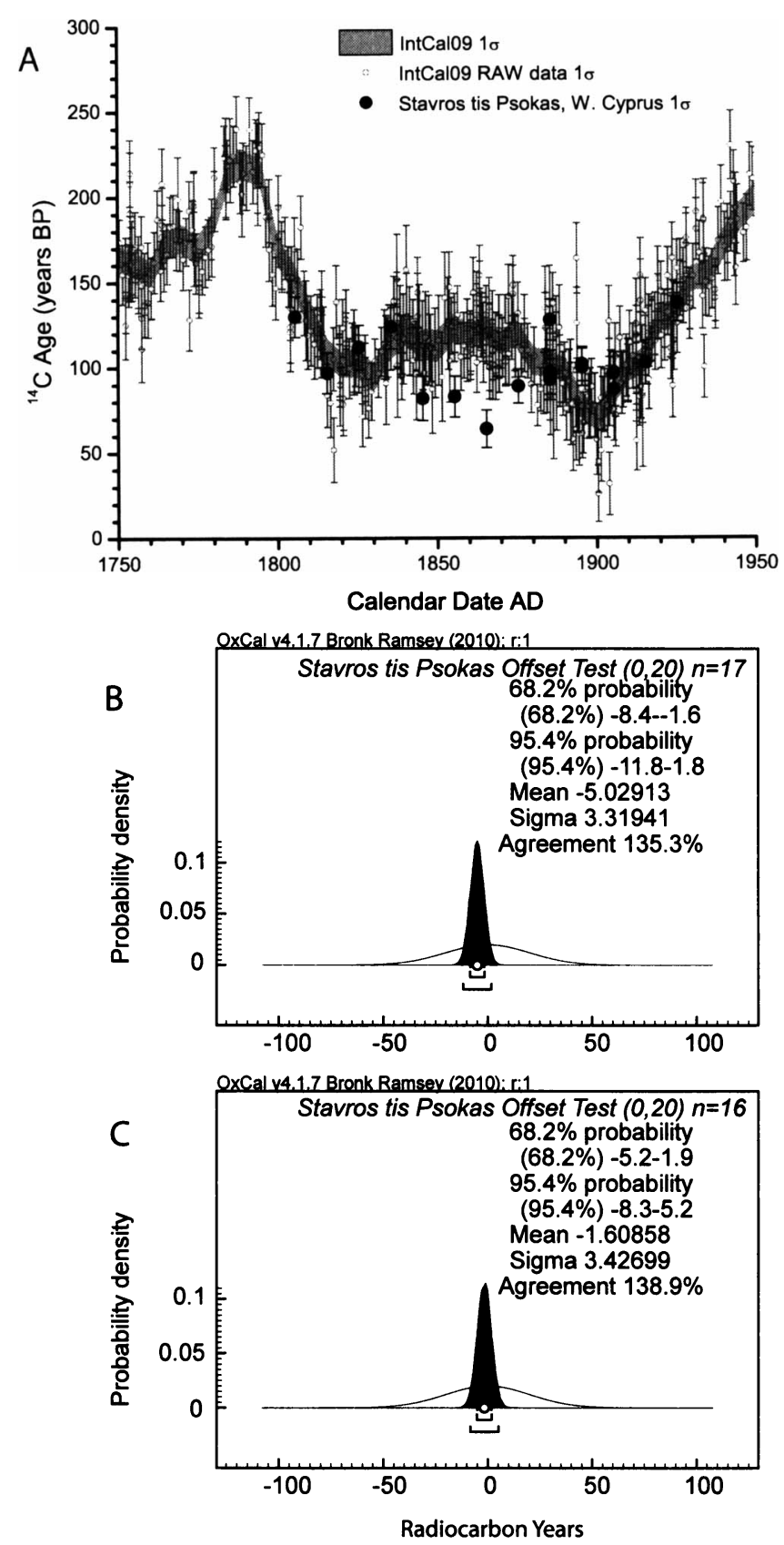

Figure 7 A. $17{ }^{14} \mathrm{C}$ dates on 12 known-age decadal samples over 130 calendar yr (AD 1801-1930) from a Pinus brutia chronology from the Stavros tis Psokas area, western Cyprus (the ${ }^{14} \mathrm{C}$ data are listed in Table 2), shown against (i) the IntCal09 $1 \sigma$ calibration curve (gray band), and (ii) the individual raw ${ }^{14} \mathrm{C}$ data comprising the IntCal09 data set for this period (data from Reimer et al. 2009). B. Typical output of a consideration of whether there is a systematic regional offset operating when comparing all the Stavros ${ }^{14} \mathrm{C}$ data $(n=17)$ sequenced at the known tree-ring intervals against IntCal09 with curve resolution set at 1 employing the $\triangle \mathrm{R}$ function in $\mathrm{OxCal}$ with a prior of $0 \pm 20 \mathrm{yr}$. C. The same as (B), but excluding the 1 major outlier (even in terms of the raw data in IntCal09)-the datum centered $\mathrm{AD}$ 1865.5. The apparent offset with the single outlier removed is very small, citing $\mu \pm \sigma$, about $-1.1 \pm 3.4{ }^{14} \mathrm{C}$ yr (and even with the outlier included it remains small at about $-5.0 \pm 3.3{ }^{14} \mathrm{C}$ yr). 
Table $2{ }^{14} \mathrm{C}$ measurements at the Heidelberg Radiocarbon Laboratory on known-age tree rings of Pinus brutia from the Stavros tis Psokas area of western Cyprus. Laboratory procedures were as summarized in Kromer et al. (2010).

\begin{tabular}{llllll}
\hline Hd code & AD start & AD end & ${ }^{14} \mathrm{C}$ age $(\mathrm{yr} \mathrm{BP})$ & SD & $\delta^{13} \mathrm{C}$ \\
\hline 25163 & 1801 & 1810 & 130 & 12 & -23.06 \\
25165 & 1811 & 1820 & 97 & 12 & -23.03 \\
25168 & 1821 & 1830 & 112 & 13 & -23.13 \\
25176 & 1831 & 1840 & 124 & 13 & -23.1 \\
25177 & 1841 & 1850 & 82 & 13 & -23.1 \\
25178 & 1851 & 1860 & 83 & 12 & -23 \\
25222 & 1861 & 1870 & 64 & 11 & -23.08 \\
25223 & 1871 & 1880 & 89 & 10 & -22.93 \\
25246 & 1881 & 1890 & 97 & 13 & -22.4 \\
25231 & 1881 & 1890 & 128 & 12 & -23.41 \\
25659 & 1881 & 1890 & 93 & 12 & -22.77 \\
25232 & 1891 & 1900 & 100 & 11 & -23.61 \\
25368 & 1891 & 1900 & 102 & 10 & -23.15 \\
25369 & 1901 & 1910 & 97 & 12 & -22.96 \\
25233 & 1901 & 1910 & 87 & 10 & -23.73 \\
25245 & 1911 & 1920 & 103 & 13 & -23.35 \\
25375 & 1921 & 1930 & 138 & 11 & -23.19 \\
\hline
\end{tabular}

Table $3{ }^{14} \mathrm{C}$ measurements at the Heidelberg Radiocarbon Laboratory on known-age tree rings of Cedrus libani from the Bcharre area, Lebanon. Laboratory procedures were as summarized in Kromer et al. (2010).

\begin{tabular}{llllll}
\hline Hd code & AD start & AD end & ${ }^{14} \mathrm{C}$ age $(\mathrm{yr}$ BP) & SD & $\delta^{13} \mathrm{C}$ \\
\hline 24438 & 1800 & 1809 & 160 & 10 & -22.32 \\
24429 & 1810 & 1819 & 111 & 14 & -22.31 \\
24396 & 1820 & 1829 & 90 & 14 & -22.38 \\
24409 & 1830 & 1839 & 99 & 12 & -22.17 \\
24436 & 1840 & 1849 & 120 & 10 & -22.04 \\
24439 & 1850 & 1859 & 131 & 10 & -22.02 \\
\hline
\end{tabular}

that are much too old and 3 that are much too recent: see Figure 9, and Manning and Kromer 2011a: Figure 1), even the remaining central 37-date set passes a $\chi^{2}$ test with a test statistic $(T)=35.9<50.3$ at $5 \%$ level for $\mathrm{df} 36$. The weighted average ${ }^{14} \mathrm{C}$ age is $3346 \pm 7 \mathrm{BP}$. If one compares the data on the 2 main sample materials (Lathyrus sp. and Hordeum sp.) from the Oxford, VERA, and Copenhagen laboratory sets $(25$ data $=$ set 3 ) (and discounting the 3 now old -in terms of when measurements were made and the laboratory procedures then in place-Heidelberg data on the basis that specific species data are not provided for 2 samples, just "grain," and as the 3 data clearly show far too much scatter (cf. Hubberten et al. 1990:184)-comprising the oldest and most recent data in the set among their 3 measurements), then we see that we achieve very similar distributions of date estimates: see Figure 10. The weighted average for the Lathyrus sp. is $3346 \pm 13 \mathrm{BP}$ ( $\chi^{2}$ test statistic of $T=$ $10.8<22.4$ at $5 \%$ level for df 13), and the weighted average for the Hordeum sp. is $3345 \pm 10 \mathrm{BP}$ ( $\chi^{2}$ test statistic of $T=8.7<16.9$ at $5 \%$ level for $\mathrm{df} 9$ ) - in other words there is no difference. The 25-date set combined has a weighted average ${ }^{14} \mathrm{C}$ age of $3346 \pm 8 \mathrm{BP}$ ( $\chi^{2}$ test statistic of $T=$ $19.8<36.4$ at $5 \%$ level for df 24 ). 

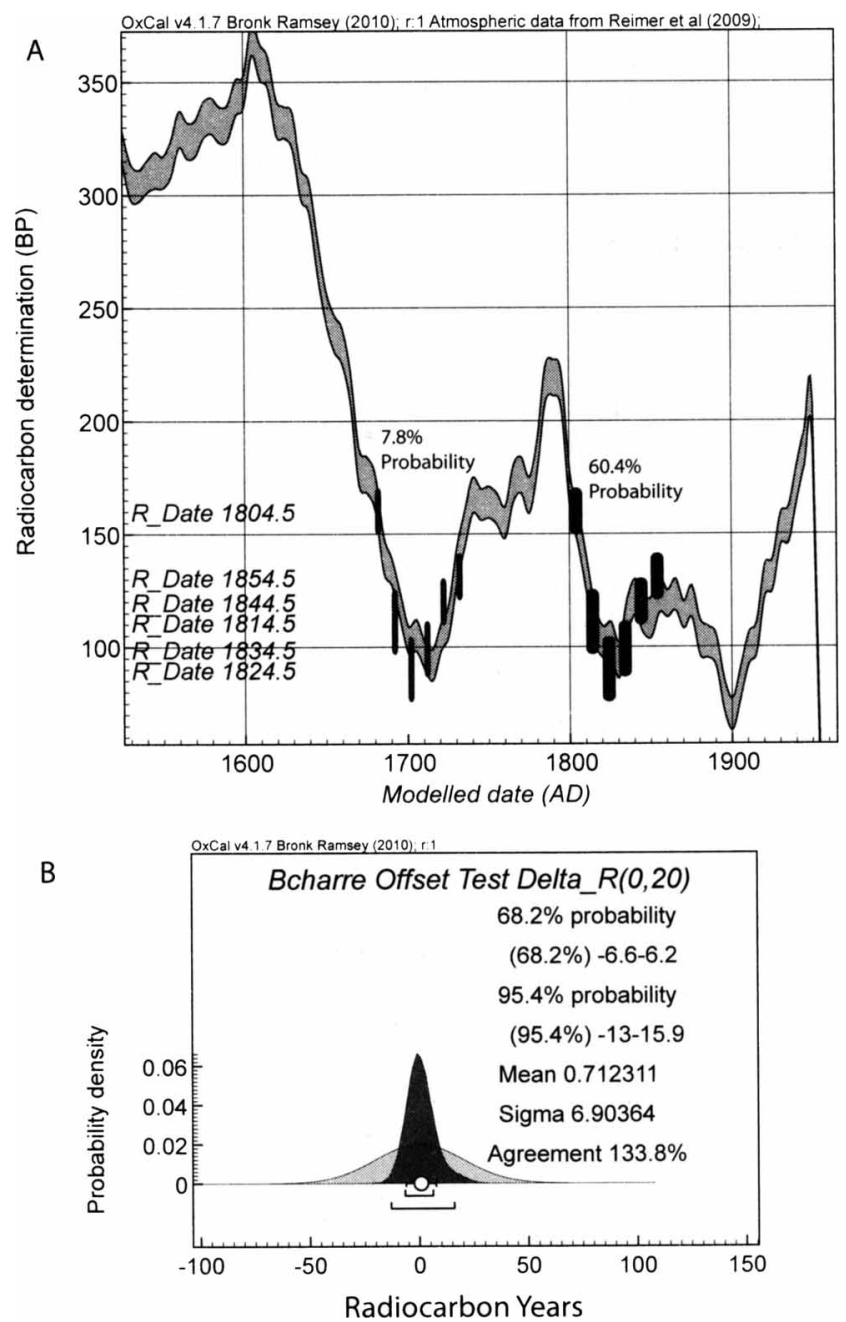

Figure 8 A. Wiggle-match placement of $6{ }^{14} \mathrm{C}$ dates on 6 known-age samples over 60 calendar yr (AD 1800-1859) from a Cedrus libani chronology from the Bcharre area, Lebanon, against the IntCal09 $1 \sigma$ calibration curve (gray band). The ${ }^{14} \mathrm{C}$ data for the Bcharre samples are listed in Table 3 . Within the most likely $68.2 \%$ probability range (and a small 0.1 rounding error), there are 2 possible wiggle-matches. The most likely one $(60.4 \%$ of the overall probability) equates with the known age date; the less likely possible fit is older ( $7.8 \%$ of the overall probability). The boxes show the 2 fits and the respective $68.2 \%$ probability ranges on the ${ }^{14} \mathrm{C}$ and calendar timescales. B. Typical output of a consideration of whether there is a systematic regional offset operating when comparing the Bcharre ${ }^{14} \mathrm{C}$ data $(n=6)$ sequenced at the known tree-ring intervals against IntCal09 with curve resolution set at 1 employing the $\Delta \mathrm{R}$ function in $\mathrm{OxCal}$ with a prior of $0 \pm 20 \mathrm{yr}$. The apparent offset is very small to zero, citing $\mu \pm \sigma, \sim 0.7 \pm 6.9{ }^{14} \mathrm{C} \mathrm{yr}$.

Thus, a priori, there is good reason to use the weighted average ${ }^{14} \mathrm{C}$ ages of $3345 \mathrm{BP}$ or $3346 \mathrm{BP}$ reviewed in the previous paragraph as the appropriate and best estimate of the correct ${ }^{14} \mathrm{C}$ age for the short-lived sample material from the Akrotiri VDL (as, for example, in the Manning et al. 2006 study). There is no evidence for an abnormally wide scatter of data looking either at the better quality data (e.g. Set 3 ) or the central $86 \%$ of the overall 43-date set (Set 1). Thus, the criterion for recognizing a possible volcanic increment-affected case suggested by Soter (2011) - "if short-lived samples from the same stratigraphic horizon yield a wide range of ${ }^{14} \mathrm{C}$ ages [our italics]..."- does not apply in this case. Since the data from the Akrotiri VDL are, in fact, rather coherent, and do not 


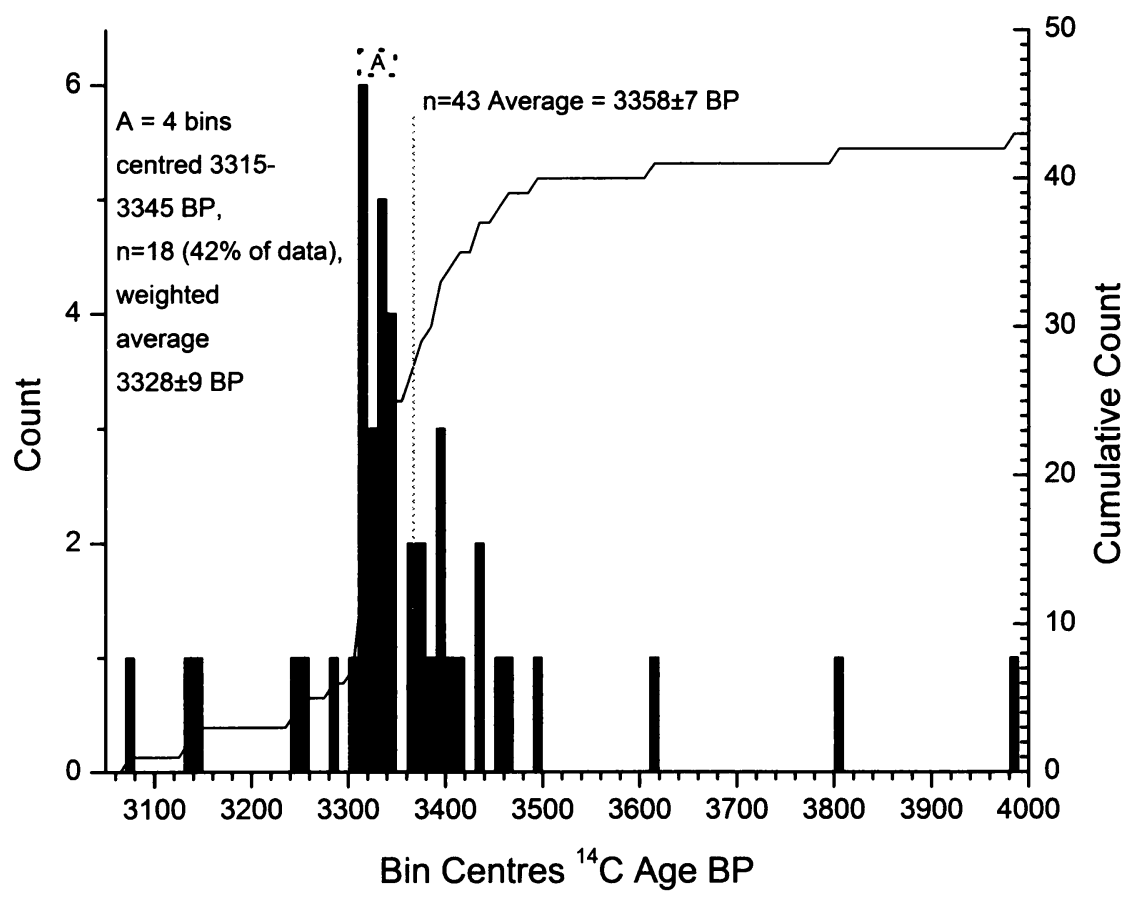

Figure 9 Thera volcanic destruction level ${ }^{14} \mathrm{C}$ data (on short-lived samples) Set $1, n=43$, frequency distribution (of central values) by $10{ }^{14} \mathrm{C}$ yr bins (set as shown in Manning and Kromer $2011 \mathrm{a}$ : Figure 1 no. 3). Data sources given in text ("Methods"). A (subjectively defined) main "low clump" of dates is indicated by the box labeled "A," comprising $41.9 \%$ of the data.

exhibit a scatter beyond that expected, it could be further argued that for the Soter suggestion of a possible volcanic-source older age increment to be nonetheless applicable then the effect needs to apply both to the Hordeum sp. and to Lathyrus sp. and so to different (original crop growing) fields and at different heights off the ground, which is perhaps unlikely. Since the ${ }^{14} \mathrm{C}$ ages on a section of olive wood found buried by the eruption (Friedrich et al. 2006) are also consistent with the dating offered by the short-lived samples from Akrotiri (see also Manning et al. 2006, 2009, 2010:1588, Figures 14-15, Table 8), then the olive tree in question (found some distance from Akrotiri and its likely fields) must also have been consistently affected and over a number of years (again seemingly unlikely, especially a stable effect over several years to decades). Hence, it could be argued that a consistent effect has to somehow apply to a large area of pre-eruption Santorini, and over some time period of weeks to months to years to decades, in order to allow the Soter suggestion - and this overall scenario is perhaps rather unlikely (and no such case has yet been observed in the field).

However, despite the strength of the case just reviewed, we offer a brief subjective discussion of whether perhaps some slight (but statistically insignificant) bias might seem to exist and, since this allows the Santorini data to support about the latest possible date they can, we review whether this has any substantive impact on the dating of the Santorini VDL_-thus, we pursue an even if case to see where this leads. This argument is based on a visual inspection of the frequency distributions of the ${ }^{14} \mathrm{C}$ data on short-lived samples from the volcanic destruction level at Akrotiri on Thera (see Figures 9 and 10), and the suggestion that the data might not be symmetrically distributed about their respective mean values. Figures 9 and 10 each indicate what we subjectively define as an apparent "clump" of a good number of tightly grouped data ( $41.9 \%$ and $52 \%$ of the data, respectively) that are 


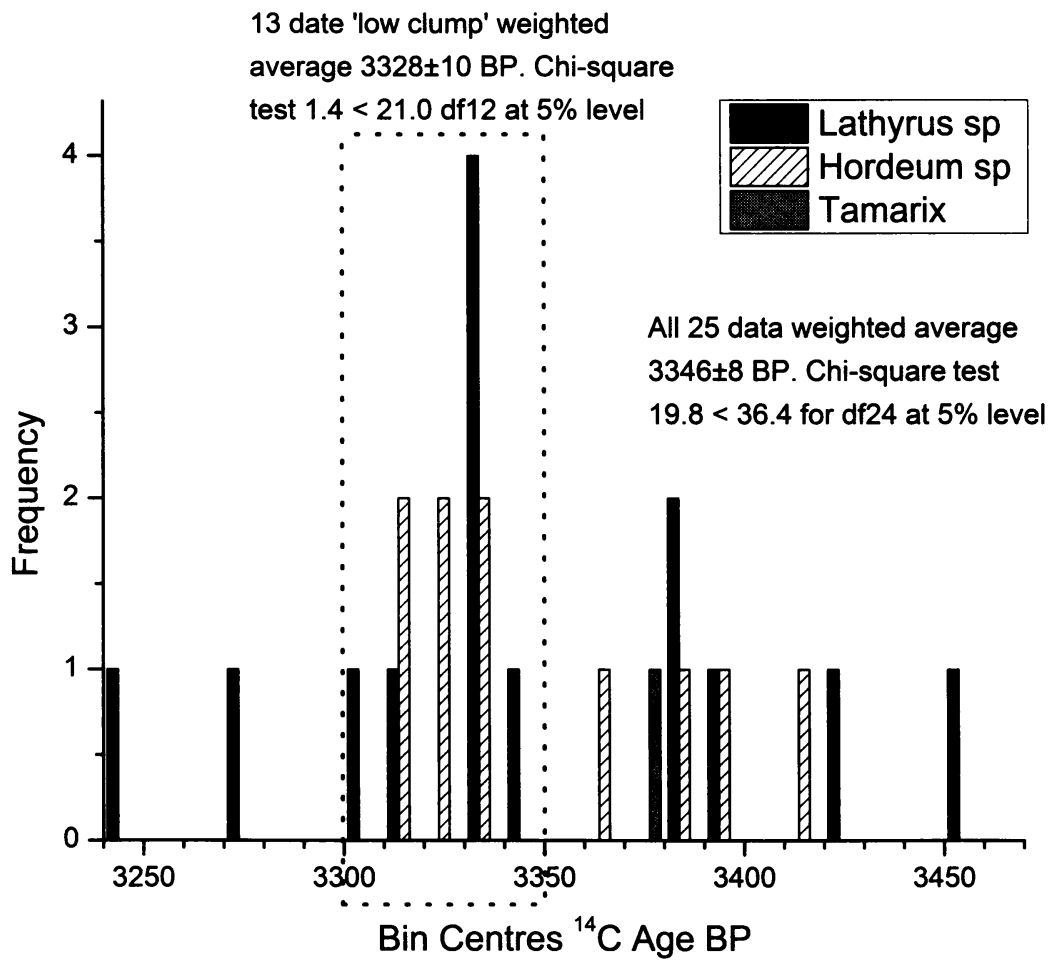

Figure 10 Thera volcanic destruction level ${ }^{14} \mathrm{C}$ data (on short-lived samples) Set $3, n=25$ (this is Set 2 from Manning et al. 2006 with the 3 Heidelberg data excluded: see text), frequency distribution (of central values) by $10{ }^{14} \mathrm{C}$ yr bins (set shown as Manning and Kromer 2011a: Figure 1 no. 1 minus the 3 Heidelberg data - data sources cited in text above "Methods"). The data are further separated by species of plant analyzed. The dotted box marks a (subjectively defined) "low clump" of data ( $52 \%$ of the total data set shown).

to the more recent side of the overall set weighted averages discussed above: thus, a weighted average value of the "low clumps" at $3328 \mathrm{BP}$ versus 3345 or $3346 \mathrm{BP}$ and a difference of $17-18{ }^{14} \mathrm{C}$ yr. We might also observe that there is more of a long tail in the data to the old side in both Figures 9 and 10. Thus, there are very few more recent data than those in the "low clump," but quite a large range of older ages. This older-age spread and "tail" might be argued to be consonant with some of these samples perhaps exhibiting (some) volcanic $\mathrm{CO}_{2}$ sourced age increments in line with the Soter (2011) arguments. If so, it is the "low date clump" (e.g. "A" in Figure 9 or the box area in Figure 10) that perhaps better reflects the best estimate available for the contemporary atmospheric ${ }^{14} \mathrm{C}$ age least altered by possible old (volcanic) $\mathrm{CO}_{2}$.

This "low date clump" of central values offers weighted average ${ }^{14} \mathrm{C}$ ages of $3328 \pm 9 \mathrm{BP}$ (Figure 9) or $3328 \pm 10 \mathrm{BP}$ (Figure 10). If one further argues only to consider the most modern available data and so only considers the 13 AD2000s data in the Manning et al. (2006) study, then this "low clump" weighted average becomes $3326 \pm 11 \mathrm{BP}$. These values are strikingly similar to the $3325 \mathrm{BP}$ value the Oxford team reported in their 1990 paper if they allowed for the possibility of the reality of an older contaminant factor in their Series I (Housley et al. 1990:213).

The calibrated calendar age ranges for $3328 \pm 9$ and $3326 \pm 11 \mathrm{BP}$ are shown in Figure 11. The most likely calendar age ranges are in the 17 th century BC (and in particular the subranges $1635-1607$ or 
1634-1606 cal BC, respectively) - thus, use of the lower ${ }^{14} \mathrm{C}$ age estimates from the subjectively defined "low date clumps" above does not materially change previous assessments of the ${ }^{14} \mathrm{C}$-based dating of the Thera volcanic destruction level that also favored mid- to later 17 th century $\mathrm{BC}$ ranges (e.g. Manning 1999; Bronk Ramsey et al. 2004; Manning et al. 2006; Friedrich et al. 2006; Friedrich and Heinemeier 2009; Heinemeier et al. 2009). However, there is now a noticeably increased possibility for a date in the later 17 th century $\mathrm{BC}$, and also for a date in the mid-16th century $\mathrm{BC}$ date range when these ${ }^{14} \mathrm{C}$ ages are considered in isolation (as in Figure 11). A date range of 1590-1532 cal $\mathrm{BC}$ has a $36.2 \%$ probability with the date $3328 \pm 9 \mathrm{BP}$ (the most likely subrange(s) looking at the $68.2 \%$ probability range is $1573-1539$ cal $\mathrm{BC}$ ) and a range $1593-1531$ cal $\mathrm{BC}$ has a $43.4 \%$ probability with the date $3326 \pm 11 \mathrm{BP}$ (the most likely subrange looking at the $68.2 \%$ probability range is $1575-1537 \mathrm{cal} \mathrm{BC}$ ).
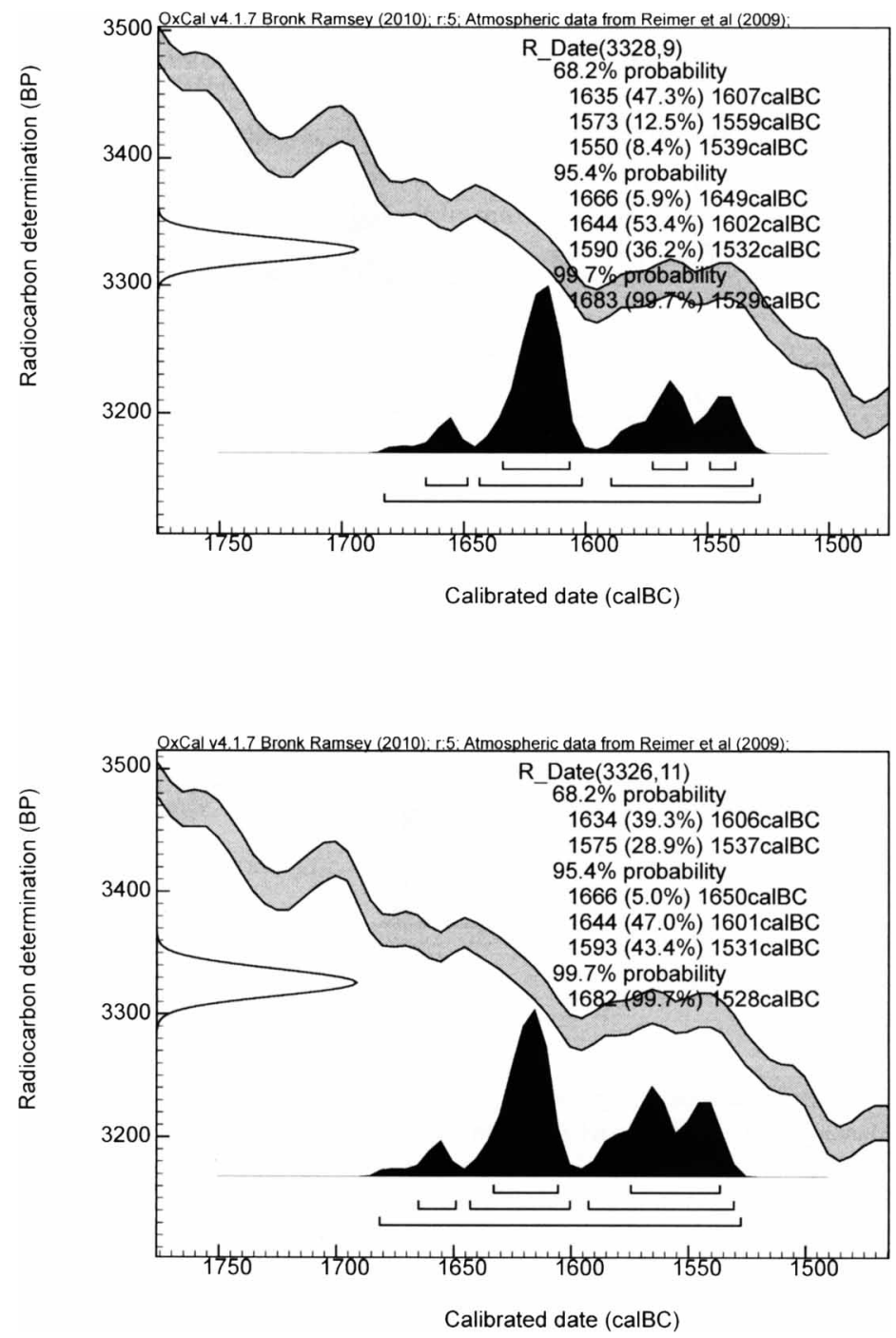

Figure 11 Calibrated calendar age ranges for 2 of the weighted averages on the "low date clump" sets identified in Figures 9-10 and in the text. Calibration analysis and data shown are from OxCal 4.1.7 (Bronk Ramscy 1995, 2009) and IntCal09 (Reimer ct al. 2009). 
If the lowest of the above "low" ${ }^{14} \mathrm{C}$ age estimates (3326 $\left.\pm 11 \mathrm{BP}\right)$ for the Thera volcanic destruction level is employed in a sequence analysis of Aegean ${ }^{14} \mathrm{C}$ data from before, contemporary with, and after the Santorini eruption horizon, as in (i) Manning et al. (2006) or (ii) Manning and Bronk Ramsey (2009) with Manning (2009), then the effect of employing the "low" Thera volcanic destruction level set is to concentrate the modeled probability for the Thera volcanic destruction level in the last few decades of the 17th century BC: see Figure 12. These ranges are a little more recent than previously reported, but remain firmly centered in the later-late 17th century $\mathrm{BC}$, with clear highest probability either 1632-1605 cal BC (Figure 12A) or 1626-1612 cal BC (Figure 12B).
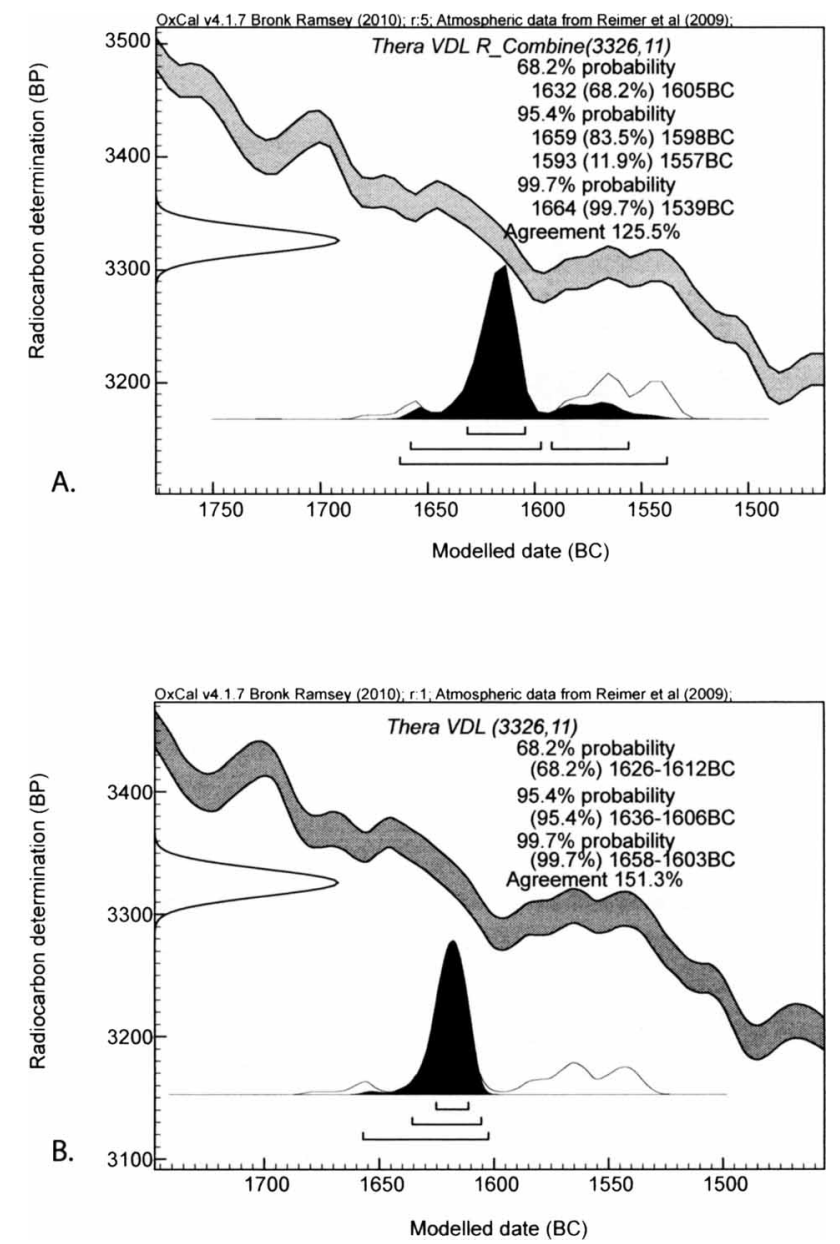

Figure $12 \mathrm{~A}$. The modeled calendar age probability distribution and age ranges for the Thera volcanic destruction level from the Manning et al. (2006) Model 1 Aegean sequence model rerun employing the lowest of the low date clump weighted average values of $3326 \pm 11 \mathrm{BP}$ for the Akrotiri VDL set of data on short-lived samples. B. As (A) but running a slightly revised version of (A) (as in Manning and Bronk Ramsey 2009) including (i) the Friedrich et al. (2006) olive branch data with last dated segment placed as contemporary with or after the Thera volcanic destruction level, and (ii) including the Late Minoan IB Final data on short-lived samples from Mochlos on Crete (as in Manning 2009) but (iii) changing the Chania phase of Late Minoan IB data to have a Tau_Boundary (which has the effect of pushing the Chania dating as late as possible). Calibration analysis and data are shown from OxCal 4.1.7 (Bronk Ramsey 1995, 2009) and IntCal09 (Reimer et al. 2009). A. with curve resolution 5; B. with curve resolution set at 1. 
A final issue concerns whether any growing-season-related regional ${ }^{14} \mathrm{C}$ offset might apply-as reviewed earlier in this paper. The available evidence from the Aegean region suggests that if any such offset exists it is negligible to very small. A possible offset factor $(\Delta R)$ from available data of no more than approximately $4 \pm 4{ }^{14} \mathrm{C}$ yr was suggested in Manning et al. (2010) and this seems if anything generous based on the evidence reviewed in Figures 4-8 above. Employing such a putative possible offset further pushes the Aegean dates as late as possible. We might nonetheless consider the effect of such a possible plausible offset factor on the analyses reported above and in Figures 11 and 12: see Table 4. If the "low date clump" Thera volcanic destruction level value is considered in isolation, this further slight reduction in the effective ${ }^{14} \mathrm{C}$ age starts to make a 16th century $\mathrm{BC}$ date range just about as likely as, or even slightly more likely than, the 17 th century $\mathrm{BC}$ date range. We are of course doing everything subjective (and beyond) possible now to the data in order to achieve as recent a calendar age as we can. The sequence analyses reported in Figure 12 if adjusted by the $\Delta \mathrm{R}$ of $4 \pm 4$ are less affected and the slightly lower calendar age ranges still very clearly resolve in favour of dates in the later-late 17th century BC (1632/1624 to 1609/1601 cal BC): see Table 4.

Table 4 Calibrated calendar age ranges calculated for the Akrotiri volcanic destruction level from the analyses shown in Figures 11-12 or similar and as discussed in the text, and the same if a $\Delta R$ offset of $4 \pm 4 \mathrm{yr}$ is applied as the possible plausible maximum relevant range of a growing-seasonrelated regional offset for the Aegean on the basis of the data in Manning et al. (2010) and as found to be a likely upper-end estimate from the analyses reported in this paper (see Figures 4-8).

\begin{tabular}{|c|c|c|}
\hline Analysis model & $68.2 \%$ probability & $95.4 \%$ probability \\
\hline \multirow[t]{3}{*}{ (a) $3328 \pm 9 \mathrm{BP}$ (in isolation) } & $1635-1607(47.3 \%)$ & $1666-1649 \quad(5.9 \%)$ \\
\hline & $1573-1559(12.5 \%)$ & $1644-1602(53.4 \%)$ \\
\hline & $1550-1539(8.4 \%)$ & $1590-1532(36.2 \%)$ \\
\hline \multirow[t]{2}{*}{ (b) as (a) but with $\Delta R$ offset of $4 \pm 4 \mathrm{yr}$} & $1631-1606(35.9 \%)$ & $1663-1653(2.6 \%)$ \\
\hline & $1576-1537(32.3 \%)$ & $\begin{array}{l}1640-1601(44.6 \%) \\
1593-1531(48.2 \%)\end{array}$ \\
\hline \multirow[t]{2}{*}{ (c) $3326 \pm 11 \mathrm{BP}$ (in isolation) } & $1634-1606(39.3 \%)$ & $1666-1650(5.0 \%)$ \\
\hline & $1537(28.9 \%)$ & $\begin{array}{l}1644-1601(47.0 \%) \\
1593-1531(43.4 \%)\end{array}$ \\
\hline \multirow[t]{2}{*}{ (d) as (c) but with $\Delta \mathrm{R}$ offset of $4 \pm 4 \mathrm{yr}$} & $1629-1606$ & $1661-1654(1.8 \%)$ \\
\hline & $1576-1537(37.1 \%)$ & $1639-1530(93.6 \%)$ \\
\hline $\begin{array}{l}\text { (e) Manning et al (2006) Model } 1 \text { with Thera VDL set } \\
\text { as } 3326 \pm 11 \mathrm{BP}\end{array}$ & $1632-1605(68.2 \%)$ & $\begin{array}{l}1659-1598(83.5 \%) \\
1593-1557(11.9 \%)\end{array}$ \\
\hline (f) as (e) but with $\Delta \mathrm{R}$ offset of $4 \pm 4 \mathrm{yr}$ & $\begin{array}{l}1632-1601(66.3 \%) \\
1571-1568(1.9 \%)\end{array}$ & $1641-1549(95.4 \%)$ \\
\hline$(\mathrm{g})=(\mathrm{e})$ modified to add Mochlos L & $1627-1612(68.2 \%)$ & $1638-1605(95.4 \%)$ \\
\hline
\end{tabular}

and Friedrich et al (2006) data on the Santorini olive

branch after Manning (2009) and Manning and Bronk

Ramsey (2009)

(h) as (g) but with $\Delta \mathrm{R}$ offset of $4 \pm 4 \mathrm{yr}$

$1624-1609(68.2 \%) \quad 1631-1600(95.4 \%)$

As a final analysis, we show a revised sequence analysis incorporating (i) the additional charcoal data from late Middle Cycladic to Late Cycladic I Advanced Akrotiri from Maniatis (2010); (ii) the lowest of the "low clump" dates for the Akrotiri VDL short-lived samples at $3326 \pm 11 \mathrm{BP}$; (iii) a Tau_Boundary for the Chania data, which has the effect of pushing these data as late as possible; (iv) the Mochlos Late Minoan IB data as in Manning (2009); and (v) a $\Delta \mathrm{R}$ allowance of $4 \pm 4$, which appears generous (see above this paper) and again helps push the resultant dates about as low as plausibly possible. The outcome is shown in Figure 13 . This places the most likely $68.2 \%$ range for 
the date of the Akrotiri VDL 1630-1605 cal BC. The 95.4\% range (1643-1559 cal BC) now includes the 16th century cal BC, but the main probability is clearly in the last 3 decades of the 17th century BC (see Figure 13 inset), and it noticeable that even now the extreme lowest end of the $95.4 \%$ probability range ends $\sim 1559$ cal $\mathrm{BC}$-well short of the conventional archaeological date estimates for the date of the Santorini/Thera eruption $\sim 1530-1500 \mathrm{BC}$. Thus, even this extreme case where we have done just about everything subjectively possible to push for as late a date as plausible does not find the conventional chronology position to be potentially compatible with the ${ }^{14} \mathrm{C}$ evidence - the ${ }^{14} \mathrm{C}$ evidence in combination with the archaeological sequence framework instead clearly offers a most likely date for the Akrotiri VDL in the last 3 decades of the 17th century BC.

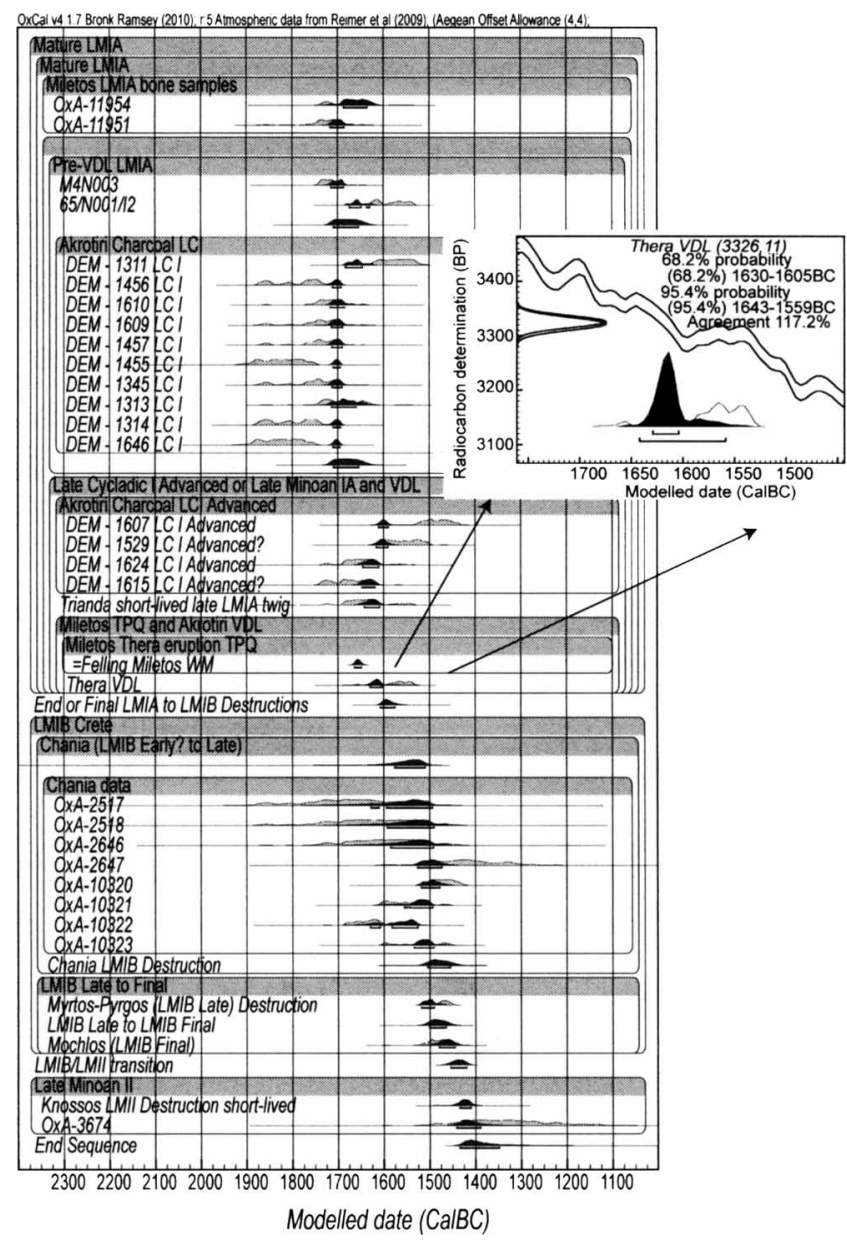

Figure 13 The modeled outcomes for the Late Minoan IA to Late Minoan II sequence from a revised version of the Manning et al. (2006) Model 1 incorporating (i) the additional charcoal data from late Middle Cycladic to Late Cycladic I Advanced contexts at Akrotiri from Maniatis (2010) = the DEM samples; (ii) the lowest of the "low clump" dates for the Akrotiri VDL short-lived samples at $3326 \pm 11 \mathrm{BP}$; (iii) a Tau_Boundary for the Chania data, which has the effect of pushing this as late as possible; (iv) the Mochlos Late Minoan IB data as in Manning (2009); and (v) allowing for a $\Delta R$ allowance of $4 \pm 4$, which appears generous (see above this paper) and again helps push the resultant dates about as low as plausibly possible. Thus, this is a "latest plausible/possible" case study, doing everything reasonable given the available data to get as late a date as possible for the Akrotiri VDL. Calibration data are from OxCal 4.1.7 (Bronk Ramsey 1995, 2009) and IntCal09 (Reimer et al. 2009) with curve resolution set at 5 . No outliers are excluded in the analysis shown. The horizontal lines under the probability histograms show the modeled $68.2 \%$ probability ranges. The inset shows the modeled age range from this analysis for the Akrotiri VDL. The most likely $68.2 \%$ probability range is $1630-1605$ cal BC. 


\section{DISCUSSION-OFFSETS}

The data, both from both known-age and floating time series as reviewed in this paper from the Aegean-Anatolian-east Mediterranean region (excluding the southern Levant and Egypt), show little evidence for any substantive, yet alone significant, offsets for these samples versus the IntCal09 data set: with $\mu \pm \sigma$ values (see Figures $4-8$ ) of $1.2 \pm 2.3,3.6 \pm 6.2,3.8 \pm 8.1,-1.6 \pm 3.4$, and $0.7 \pm 6.9$ ${ }^{14} \mathrm{C}$ yr. It could argued that the possible Aegean offset factor of around $4 \pm 4{ }^{14} \mathrm{C}$ yr suggested in Manning et al. (2010) is if anything about a maximum possible factor. The weighted average of the $\mu \pm \sigma$ offset findings in Figures 4-8 for the Aegean-Anatolian-east Mediterranean region is $0.75 \pm 1.72-$ i.e. effectively 0 .

These findings are on the basis of tree-ring data. They are clearly reasonable for these data as typical tree growth (at the relevant moderate to higher elevations) in the Aegean-Anatolian-east Mediterranean region (excluding the southern Levant and Egypt) occurs generally at around the same time as in the rest of the mid-latitude Northern Hemisphere, with at most only a slight offset (sometimes starting slightly earlier in the spring and ending a little earlier in the summer). A legitimate question is whether these tree-ring-based data apply also to field crops from lower elevations (like Hordeum $\mathrm{sp}$. and Lathyrus sp.)? Where these crops are growing above ground in (early) spring onwards for an early to mid-summer harvest-with summer the typical harvest time for traditional farming in the Mediterranean (see e.g. Spurr 1986; Isager and Skydsgaard 1992) - then the answer should broadly be yes. Where the crop was planted in the autumn perhaps a little more offset may occur. For example, as an approximate test, we can consider $\Delta^{14} \mathrm{C}$ data on samples of barley and wheat collected in the field in March and June 2004 in southern and central Cyprus at lower elevations versus the monthly atmospheric $\Delta^{14} \mathrm{C}$ record from Mauna Loa, Hawaii (Graven et al. 2012): see Figure 14

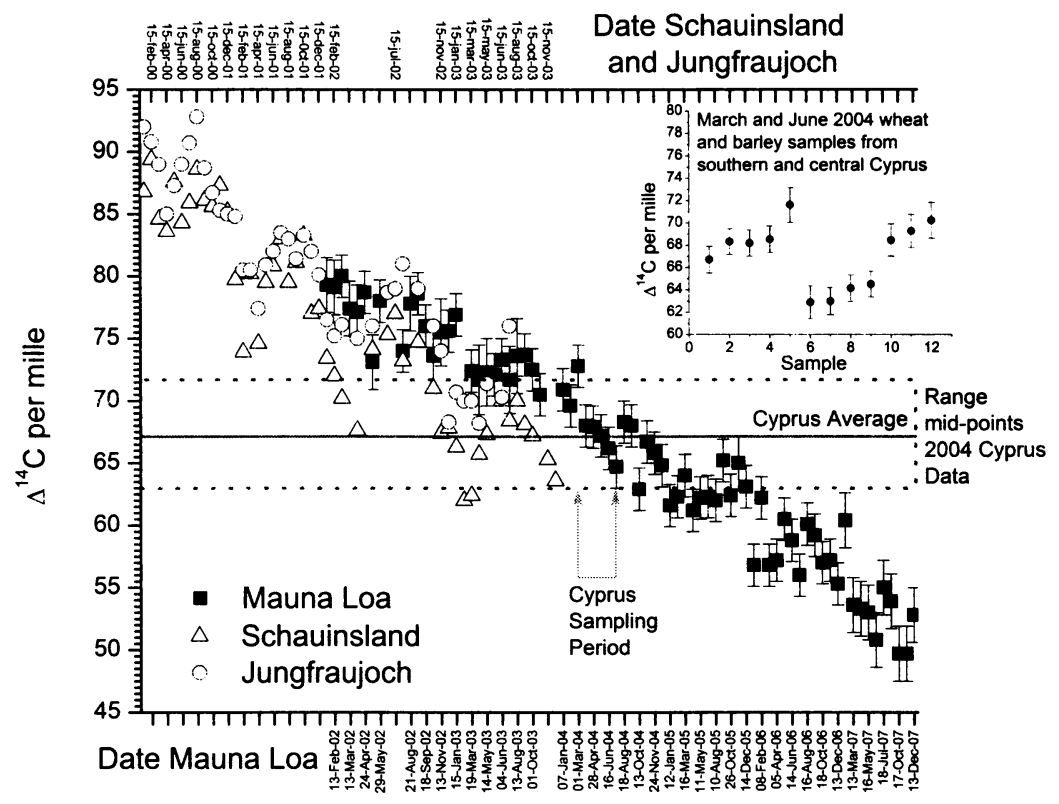

Figure 14 Comparison of the range and (non-weighted) average of $\Delta^{14} \mathrm{C}$ measurements on wheat and barley samples collected from southern and central Cyprus in March (samples 1-5) and June 2004 (samples 6-12) made at the Heidelberg Radiocarbon Laboratory versus the $\Delta^{14} \mathrm{C}$ record from Mauna Loa, Hawaii (Graven et al. 2012), and the monthly average $\Delta^{14} \mathrm{C}$ values from Schauinsland and Jungfraujoch, Germany (Levin and Kromer 2004). The $12 \Delta^{14} \mathrm{C}$ measurements from the Heidelberg Radiocarbon laboratory on samples of wheat (nos. 1, 2, 5, 6, 9, 10,11, 12) and barley (nos. 3, 4, 7, 8) collected in the field (pre-harvest) at sites from southern and central Cyprus are shown in the inset (order by ${ }^{14} \mathrm{C}$ values obtained for March set, samples 1-5, and then for June set, samples 6-12). For data: see Table 5. Error bars shown are $1 \sigma$. 
(individual Cyprus data shown in the inset) and Table 5. We see a general broad correlation. There is of course some variation, but the data from both loci are consistent with the 2004 sampling period (and there is a slight tendency in the Cyprus data for larger values for the spring [March] versus early summer [June] samples). We can also compare the Mauna Loa record with 2 records from Germany from Schauinsland and Jungfraujoch (Levin and Kromer 2004)-all 3 records partly overlap-and against the Cyprus data: see Figure 14. Again, while there is a clear trend in the data, there is variation on the short-term scale-but the Cyprus data clearly match within their correct date window and could not be misplaced by more than 1-2 calendar yr. The Cyprus data are from the types of crops providing typical short-lived samples from archaeological contexts and were collected, subjectively, from barley and wheat crops in various states of growth in each of March and June 2004. The implication of this case is that typical summer-harvested crops from the eastern Mediterranean should offer ${ }^{14} \mathrm{C}$ ages with at most only very small (and thus largely negligible and unimportant) offsets in ${ }^{14} \mathrm{C}$ age versus those from the contemporary general mid-latitudes of the Northern Hemisphere. And thus, in turn, trees from the eastern Mediterranean region that sample their ${ }^{14} \mathrm{C}$ content each year over approximately the same spring to summer period should, within small margins, provide an equivalent record-hence, the findings for Aegean-Anatolian-east Mediterranean (excluding the southern Levant and Egypt) offsets above from tree rings should also hold for most summer-harvested crops in the region in approximate terms.

Table $5 \Delta^{14} \mathrm{C}$ measurements from the Heidelberg Radiocarbon laboratory on samples of wheat and barley collected in the field (pre-harvest, in a range of the growth stages available at each sampling period) at sites from southern and central Cyprus, elevations $\sim 25$ to $300 \mathrm{~m}$ asl.

\begin{tabular}{lllll}
\hline Sample nr & Hd lab code & $\delta^{13} \mathrm{C}$ & $\Delta^{14} \mathrm{C}$ & SD \\
\hline March 2004 Barley & & & & \\
3 & 24128 & -25.04 & 68.19 & 1.17 \\
4 & 23727 & -24.95 & 68.54 & 1.20 \\
March 2004 Wheat & & & & \\
1 & 24125 & -25.02 & 66.72 & 1.20 \\
2 & 23718 & -25.01 & 68.33 & 1.16 \\
5 & 23750 & -24.88 & 71.61 & 1.54 \\
June 2004 Barley & & & & \\
7 & 23714 & -25.48 & 62.99 & 1.22 \\
8 & 24126 & -25.28 & 64.15 & 1.20 \\
June 2004 Wheat & & & & \\
6 & 23748 & -26.10 & 62.89 & 1.47 \\
9 & 24112 & -26.00 & 64.51 & 1.15 \\
10 & 24138 & -24.82 & 68.46 & 1.45 \\
11 & 23751 & -24.93 & 69.28 & 1.49 \\
12 & 24139 & -24.90 & 70.23 & 1.60 \\
\hline
\end{tabular}

\section{DISCUSSION-SANTORINI DATING}

If the subjective decision is made to prefer the (subjectively) observable "low date clump" of Akrotiri volcanic destruction data on short-lived samples as more likely representing the correct contemporary ${ }^{14} \mathrm{C}$ age of this time horizon-a possible hypothesis following Soter (2011) but one that has not actually been demonstrated - then we find that, in terms of the analysis of a sequence of southern Aegean ${ }^{14} \mathrm{C}$ data (Figures $12-13$ and Table 4), the likely date for the Santorini volcanic eruption horizon lies, in round terms, in the last 3 decades of the 17 th century $\mathrm{BC}$. It is important to highlight that such a comprehensive Bayesian approach (i.e. using the approaches summarized in 
e.g. Bayliss et al. 2007, 2011; Bayliss 2009) is the most appropriate and rigorous approach available for such data, and provides both considerable analytical power and robustness in the case of such a detailed sequence analysis. To do the opposite, and to consider 1 date, or group of dates, in isolation, and to ignore the relationships with other data known to be earlier or later (from stratigraphic or archaeological analysis), and especially to further favor an extreme end of a probability distribution in isolation, is inappropriate and/or invalid. It is also important to note how robust the finding in favor of the later/late 17 th century $\mathrm{BC}$ is for the Akrotiri VDL, whether employing the ${ }^{14} \mathrm{C}$ data as published/reported, or whether trying to allow for a range of various possible plausible issues (see above, and also Manning and Bronk Ramsey 2003:124-9; Manning et al. 2006, 2009; Manning and Kromer 2011a).

By preferring a late 17 th century $\mathrm{BC}$ date range, we find a result that is more easily potentially compatible with a revised interpretation of the east Mediterranean archaeological synchronizations (e.g. Kemp and Merrillees 1980; Betancourt 1987; Manning 1988, 1999, 2007, 2009; Manning et al. 2006; Manning and Bronk Ramsey 2009; Manning and Kromer 2011a)—whereas an earlier date into the mid-17th century BC causes many more problems and contradictions (see for example the comments of Merrillees 2009: esp. 251). Such a late 17th century BC date range is also consonant with-and more so than a mid-17th century $\mathrm{BC}$ date-the relevant Aegean ${ }^{14} \mathrm{C}$ evidence available excluding the ${ }^{14} \mathrm{C}$ data from Santorini (Manning et al. 2006: Table 1; Wild et al. 2010; Lindblom and Manning 2011). The analysis of the Santorini ${ }^{14} \mathrm{C}$ data in terms of a sequence of ${ }^{14} \mathrm{C}$ data from before, contemporary with, and after the Santorini eruption horizon is the most appropriate and robust approach (as in Manning 2006, 2009; Manning and Bronk Ramsey 2009; Manning et al. 2009 , and as now adapted in this paper to consider the possible relevance and impact of favoring, subjectively, the "low date clump" identified in the Akrotiri VDL data as perhaps more relevant to the correct ${ }^{14} \mathrm{C}$ age of this context). Thus, the late 17 th century $\mathrm{BC}$ solution appears (to remain) the best, most robust date placement of the Santorini eruption on current evidence (and even doing everything to push for as late a date as plausible). Such a date accords well with the date range suggested for the last growth increment of an olive tree branch plausibly killed and buried by the Santorini eruption (Friedrich et al. 2006; Friedrich and Heinemeier 2009; Manning et al. 2009:312, Table 3; Manning 2010:465; Manning et al. 2010: Figure 14, Table 8). The ice-core signal that has been argued to be possibly associated with the Santorini eruption (despite criticisms) by Vinther et al. $(2006,2008)$ is published as dating $\sim 1642 \mathrm{BC}$, but an apparent dating problem (unexplained) exists that could see the ice-core date reduced by $\sim 20 \mathrm{yr}$ (Muscheler 2009), potentially also placing it into the same time period. (Other associations suggested from tree-ring anomalies [and exactly which ones?], or changes in speleo-them chemistry, might also come into play, but as yet they either lack a definite causal association with Santorini, or have some flexibility in their chronology and, thus, we do not discuss them here: see Manning 2010:466-7.)

If, however, one chooses to ignore the Aegean Late Minoan I-II sequence, and the indications that the various phases of the subsequent Late Minoan IB period progressively seem to occupy parts of the mid- and later 16th century BC and earlier to mid-15th century BC (Manning 2009; see also Figure 13 above), then the Santorini evidence considered in isolation employing the "low date clump"-as in Figure 12-clearly most strongly favors a late 17 th century BC date range but does also now permit a mid-16th century BC range with much more probability $(36.2 \%$ to $43.4 \%$ in Figure 11). And, if in addition, a possible plausible maximum $\Delta \mathrm{R}$ offset of $4 \pm 4 \mathrm{yr}$ is included to help even more, then the 16th century $\mathrm{BC}$ date range becomes as likely as, or even more likely than, the 17 th century BC date range: Table 4 . Those scholars who would prefer a lower date for the Santorini eruption horizon will undoubtedly seize on this (and ignore the preceding paragraph and the analytical strength and robustness of the Bayesian sequence approach and the need to allow for the clear 
date placement of the range of Late Minoan IB data). Nonetheless, the notable point is that the possible calendar range ends $1532-1530 \mathrm{cal} \mathrm{BC}$ at $95 \%$ probability (and 1529-1527 cal BC even at $99.7 \%$ probability). Thus, the date of about $1530 \mathrm{BC}$ for the Santorini eruption recently suggested by Warren (2010:394) on the basis of his assessment of the archaeological evidence is at the lowest possible end margin of the ${ }^{14} \mathrm{C}$ evidence--something that is inherently very unlikely. The ${ }^{14} \mathrm{C}$-supported range (even at its margin and doing everything plausible to achieve the most recent age possible) does not run into the mid-1520s BC, let alone to $1500 \mathrm{BC}$ or later (for just a few examples of scholarship arguing for conventional or "low" dates for the Santorini eruption in this post- ${ }^{14} \mathrm{C}$ range, see Bietak 2003; Bietak and Höflmayer 2007; Wiener 2006, 2009a,b, 2010; MacGillivray 2009). This ${ }^{14} \mathrm{C}$-based date range, even choosing to select the lowest possible calibrated date, is thus not compatible with the conventional archaeological date assessments for the Santorini eruption from around 1525 to $1500 \mathrm{BC}$ or later. This time range is associated instead with subsequent Late Minoan IB ${ }^{14} \mathrm{C}$ evidence (Manning 2009; see also Figure 13 above). As shown in Figure 13, the Chania Late Minoan IB data lie in the mid-late 16th century BC, the Late Minoan IB Late destruction at MyrtosPyrgos (i.e. end of Late Minoan IB Late at Myrtos-Pyrgos-with the actual Late Minoan IB Late cultural phase before this point, and before this the earlier part(s) of the overall Late Minoan IB cultural phase) is then placed $\sim 1519-1491 \mathrm{cal}$ BC at $68.2 \%$ probability $(1526-1465 \mathrm{cal} \mathrm{BC}$ at $95.4 \%$ probability), and the subsequent Late Minoan IB Final destruction at Mochlos lies at $1480-1446$ cal BC at $68.2 \%$ probability (1498-1436 cal BC at $95.4 \%$ probability). The mature-late Late Minoan IA Akrotiri VDL cannot also be pushed into the later 16th century BC; it creates an unacceptable conflict of evidence. In reverse, the ${ }^{14} \mathrm{C}$ placements of the end of the Late Minoan IB period in the earlier to mid-15th century BC, and the Late Minoan II period in the later 15th century BC (see Figure 13), offer good correspondences with the historically derived dates for the Egyptian contexts with which reasonable numbers of material culture and other exchanges (Aegean to/from Egypt and the Levant) relevant to these periods are associated (Höflmayer 2009; Manning 2009)—in particular for a transition between Late Minoan IB and Late Minoan II during the reign of Tuthmosis III.

For those who wish to try to hold as close to the conventional "low" archaeological chronology as possible, while accepting the need to try to find some sort of accommodation with the ${ }^{14} \mathrm{C}$ evidence (even if choosing an unlikely possibility), the available "low"-date option is to try to make a possible plausible argument in favor of a date for the Santorini eruption somewhere in a range from about 1593 to $1530 \mathrm{cal}$ BC (looking at the Santorini evidence in isolation), with the area offering the most plausible (some probability) date closest to the conventional archaeological assessment lying from about 1550 to $1539 / 1537$ cal BC. To employ such a date for the Santorini eruption would still require a substantial revision and rethinking of a number of the conventional Aegean-Egyptian linkages, and especially of viewpoints that place archaeological traits that are at a minimum contemporary with the Santorini eruption, and/or from shortly after it, as lying in the 15 th century BC, and in particular from the start of the reign of Tuthmosis III ( 1479 BC) (such as are summarized in Bietak 2003; Bietak and Höflmayer 2007; MacGillivray 2009). It still broadly requires a $25-$ to $50-y r$ rethink and "compromise" Aegean high chronology scenario. It could also lead to the renewal of attempts to link the Santorini eruption with the Tempest Stele of Ahmose (Foster and Ritner 1996). For some suggestions of a need to indeed rethink the conventional chronology, and the inherent associations and assumptions, see Höflmayer (this volume).

In conclusion, a reappraisal of the Akrotiri volcanic destruction level ${ }^{14} \mathrm{C}$ data set from short-lived samples, in light of the paper of Soter (2011), suggests that a dating for the Santorini volcanic eruption in the late 17th century $\mathrm{BC}$ remains most likely: in particular somewhere in the last 3 decades of the 17 th century $\mathrm{BC}$. This analysis and position gives primacy to the ${ }^{14} \mathrm{C}$ evidence and the analysis of this in terms of the available stratigraphically defined sequence (thus, the ${ }^{14} \mathrm{C}$ and archaeolog- 
ical evidence integrated together). This date range should remain the working hypothesis for those who place weight on the now detailed and sophisticated ${ }^{14} \mathrm{C}$ chronology available for this period. Moreover, this dating is relatively robust. We also know that sophisticated ${ }^{14} \mathrm{C}$ dating works very well in Egypt and offers a close match with the historical chronology (Bronk Ramsey et al. 2010). This means that a sophisticated ${ }^{14} \mathrm{C}$-based chronology from the Aegean should provide the appropriate placement of the Aegean and other east Mediterranean archaeological phases and contexts both in calendar time and against the Egyptian historical chronology (Manning and Kromer 2011a): thus, like against like. ${ }^{14} \mathrm{C}$ therefore approaches the point where it offers a refined timeframe for the $2 \mathrm{nd}$ millennium BC Aegean independent of the various assumptions, interpretations, and stepwise logic transfers inherent in the previous archaeological syntheses and derived chronologies (and especially in cases-like the Middle Minoan III through earlier Late Minoan IB periods-where there are very few import/exports between the Aegean and Egypt and instead much guesswork and assumption).

\section{ACKNOWLEDGMENTS}

We thank NSERC Canada, INSTAP, and Cornell University for support towards the ${ }^{14} \mathrm{C}$ work reported here from the East Mediterranean Radiocarbon (inter-)Comparison Project. Sampling in 2004 in Cyprus was carried out while SWM was working on a grant from the CBRL. For work and assistance with tree-ring samples, we especially thank Maryanne Newton, Jennifer Watkins, and Charlotte Pearson. For collaboration with regard to German oak samples, we thank Michael Friedrich.

\section{REFERENCES}

Bayliss A. 2009. Rolling out revolution: using radiocarbon dating in archaeology. Radiocarbon 51(1):12347.

Bayliss A, Bronk Ramsey C, van der Plicht J, Whittle A. 2007. Bradshaw and Bayes: towards a timetable for the Neolithic. Cambridge Journal of Archaeology 17(S1):1-28.

Bayliss A, van der Plicht J, Bronk Ramsey C, McCormac G, Healy F, Whittle A. 2011. Towards generational time-scales: the quantitative interpretation of archaeological chronologies. In: Whittle A, Healy F, Bayliss A, editors. Gathering Time: Dating the Early Neolithic Enclosures of Southern Britain and Ireland. Oxford: Oxbow Books. p 17-59.

Betancourt PP. 1987. Dating the Aegean Late Bronze Age with radiocarbon. Archaeometry 29:45-9.

Bietak M. 2003. Science versus archaeology: problems and consequences of high Aegean chronology. In: Bietak M, editor. The Synchronisation of Civilisations in the Eastern Mediterranean in the Second Millennium B.C. - II. Vienna: Österreichischen Akademie der Wissenschaften. p 23-33.

Bietak M, Höflmayer F. 2007. Introduction: high and low chronology. In: Bietak M, Czerny E, editors. The Synchronisation of Civilizations in the Eastern Mediterranean in the Second Millennium B.C. - III. Vienna: Österreichischen Akademie der Wissenschaften. p 13-23.

Bronk Ramsey C. 1995. Radiocarbon calibration and analysis of stratigraphy: the OxCal program. Radiocarbon 37(2):425-30.

Bronk Ramsey C. 2008. Deposition models for chronological records. Quaternary Science Reviews 27(1-2): 42-60.

Bronk Ramsey C. 2009a. Bayesian analysis of radiocarbon dates. Radiocarbon 51(2):337-60.

Bronk Ramsey C. 2009b. Dealing with outliers and offsets in radiocarbon dating. Radiocarbon 51(3):102345.

Bronk Ramsey C, Manning SW, Galimberti M. 2004. Dating the volcanic eruption at Thera. Radiocarbon 46(1):325-44.

Bronk Ramsey C, Dee MW, Rowland JM, Higham TFG, Harris SA, Brock FA, Quiles A, Wild EM, Marcus ES, Shortland AJ. 2010. Radiocarbon-based chronology for Dynastic Egypt. Science 328(5985):1554-7.

Dee MW, Brock F, Harris SA, Bronk Ramsey C, Shortland AJ, Higham TFG, Rowland JM. 2010. Investigating the likelihood of a reservoir offset in the radiocarbon record for ancient Egypt. Journal of Archaeological Science 37(4):687-93.

Dee MW, Bronk Ramsey C, Shortland AS, Higham TFG, Rowland JM. 2009. Reanalysis of the chronological discrepancies obtained by the Old and Middle Kingdom Monuments Project. Radiocarbon 51(3):106170.

Foster KP, Ritner RK. 1996. Texts, storms, and the Thera eruption. Journal of Near Eastern Studies 55:1-14.

Friedrich M, Remmel S, Kromer B, Hofmann J, Spurk M, Kaiser KF, Orcel C, Küppers M. 2004. The 12,460year Hohenheim oak and pine tree-ring chronology from central Europe - a unique annual record for ra- 
diocarbon calibration and paleoenvironment reconstructions. Radiocarbon 46(3):1111-22.

Friedrich WL, Heinemeier J. 2009. The Minoan eruption of Santorini radiocarbon dated to $1613 \pm 13 \mathrm{BC}$. In: Warburton DA, editor. Time's Up! Dating the Minoan Eruption of Santorini. Acts of the Minoan Eruption Chronology Workshop, Sandbjerg November 2007 Initiated by Jan Heinemeier \& Walter L. Friedrich. Monographs of the Danish Institute at Athens Volume 10. Athens: The Danish Institute at Athens. p 56-63.

Friedrich WL, Wagner P, Tauber H. 1990. Radiocarbon dated plant remains from the Akrotiri excavation on Santorini, Greece. In: Hardy DA, Renfrew AC, editors. Thera and the Aegean World III. Volume Three: Chronology. London: The Thera Foundation. p 18896.

Friedrich WL, Kromer B, Friedrich M, Heinemeier J, Pfeiffer T, Talamo S. 2006. Santorini eruption radiocarbon dated to $1627-1600$ B.C. Science 312(5773): 548.

Galimberti M, Bronk Ramsey C, Manning SW. 2004. Wiggle-match dating of tree-ring sequences. Radiocarbon 46(2):917-24.

Graven HD, Guilderson TP, Keeling RF. 2012. Observations of radiocarbon in $\mathrm{CO}_{2}$ at seven global sampling sites in the Scripps flask network: analysis of spatial gradients and seasonal cycles. Journal of Geophysical Research 117:D02303, doi:10.1029/2011JD016535. Data from http://scrippsco2.ucsd.edu/data/ flask_co2_and_isotopic/daily_iso/mlo_c14indiv.csv. Accessed September 2011.

Hardy DA, Renfrew AC, editors. 1990. Thera and the Aegean World III. Volume Three: Chronology. London: The Thera Foundation.

Heinemeier J, Friedrich WL, Kromer B, Bronk Ramsey C. 2009. The Minoan eruption of Santorini radiocarbon dated. In: Warburton DA, editor. Time's Up! Dating the Minoan Eruption of Santorini. Acts of the Minoan Eruption Chronology Workshop, Sandbjerg November 2007 Initiated by Jan Heinemeier \& Walter L. Friedrich. Monographs of the Danish Institute at Athens Volume 10. Athens: The Danish Institute at Athens. p 285-93.

Höflmayer F. 2009. Aegean-Egyptian synchronisms and radiocarbon chronology. In: Warburton DA, editor. Time's Up! Dating the Minoan eruption of Santorini. Acts of the Minoan Eruption Chronology Workshop, Sandbjerg November 2007 Initiated by Jan Heinemeier \& Walter L. Friedrich. Monographs of the Danish Institute at Athens Volume 10. Athens: The Danish Institute at Athens. p 187-95.

Höflmayer F. 2012. The date of the Minoan Santorini eruption: quantifying the "offset." Radiocarbon, these proceedings.

Hornung E, Krauss R, Warburton DA, editors. 2006. Ancient Egyptian Chronology. Leiden: Brill.

Housley RA, Hedges REM, Law IA, Bronk CR. 1990.
Radiocarbon dating by AMS of the destruction of Akrotiri. In: Hardy DA, Renfrew AC, editors. Thera and the Aegean World III. Volume Three: Chronology. London: The Thera Foundation. p 207-15.

Huber PJ. 2011. The astronomical basis of Egyptian chronology of the second millennium BC. Journal of Egyptian History 4:172-227.

Hubberten H-W, Bruns M, Calamiotou M, Apostolakis C, Filippakis S, Grimanis A. 1990. Radiocarbon dates from the Akrotiri excavations. In: Hardy DA, Renfrew AC, editors. Thera and the Aegean World III. Volume Three: Chronology. London: The Thera Foundation. p 179-87.

Isager S, Skydsgaard JE. 1992. Ancient Greek Agriculture: An Introduction. London: Routledge.

Keenan DJ. 2002. Why early-historical radiocarbon dates downwind from the Mediterranean are too early. Radiocarbon 44(1):225-37.

Kemp BJ, Merrillees RS. 1980. Minoan Pottery in Second Millennium Egypt. Mainz am Rhein: Philipp von Zabern.

Kromer B, Manning SW, Kuniholm PI, Newton MW, Spurk M, Levin I. 2001. Regional ${ }^{14} \mathrm{CO}_{2}$ offsets in the troposphere: magnitude, mechanisms, and consequences. Science 294(5551):2529-32.

Kromer B, Manning SW, Friedrich M, Talamo S, Trano N. $2010 .{ }^{14} \mathrm{C}$ calibration in the 2 nd and 1 st millennia BC - Eastern Mediterranean Radiocarbon Comparison Project (EMRCP). Radiocarbon 52(3):875-86.

Kutschera W, Stadler P. 2000. ${ }^{14} \mathrm{C}$ Dating for absolute chronology of eastern Mediterranean cultures in the second millennium $\mathrm{BC}$ with accelerator mass spectrometry. In: Bietak M, editor. The Synchronisation of Civilisations in the Eastern Mediterranean in the Second Millennium B.C. - I. Vienna: Österreichische Akademie der Wissenschaften. p 68-81.

Levin I, Kromer B. 2004. The tropospheric ${ }^{14} \mathrm{CO}_{2}$ level in mid-latitudes of the Northern Hemisphere (19592003). Radiocarbon 46(3): 1261-72.

Lindblom M, Manning SW. 2011. The chronology of the Lerna shaft graves. In: Gauß W, Lindblom M, Smith RAK, Wright JC, editors. Our Cups Are Full: Pottery and Society in the Aegean Bronze Age. Papers Presented to Jeremy B. Rutter on the Occasion of his 65 th Birthday. BAR International Series 2227. Oxford: Archaeopress. p 140-53.

MacGillivray JA. 2009. Thera, Hatshepsut, and the Keftiu: crises and response. In: Warburton DA, editor. Time's Up! Dating the Minoan eruption of Santorini. Acts of the Minoan Eruption Chronology Workshop, Sandbjerg November 2007 Initiated by Jan Heinemeier \& Walter L. Friedrich. Monographs of the Danish Institute at Athens Volume 10. Athens: The Danish Institute at Athens. p 154-70.

Maniatis Y. 2010. New radiocarbon dates from Akrotiri, Thera. Pasiphae 4:41-52.

Manning SW. 1988. The Bronze Age eruption of Thera: 
absolute dating, Aegean chronology and Mediterranean cultural interrelations. Journal of Mediterranean Archaeology 1(1):17-82.

Manning SW. 1999. A Test of Time: The Volcano of Thera and the Chronology and History of the Aegean and East Mediterranean in the Mid-Second Millennium $B C$. Oxford: Oxbow Books.

Manning SW. 2007. Clarifying the 'high' v. 'low' Aegean/Cypriot chronology for the mid second millennium $\mathrm{BC}$ : assessing the evidence, interpretive frameworks, and current state of the debate. In: Bietak M, Czerny E, editors. The Synchronisation of Civilizations in the Eastern Mediterranean in the Second Millennium B.C. - III. Vienna: Österreichische Akademie der Wissenschaften. p 101-37.

Manning SW. 2009. Beyond the Santorini eruption: some notes on dating the Late Minoan IB period on Crete, and implications for Cretan-Egyptian relations in the 15 th century BC (and especially LMII). In: Warburton DA, editor. Time's Up! Dating the Minoan Eruption of Santorini. Acts of the Minoan Eruption Chronology Workshop, Sandbjerg November 2007 Initiated by Jan Heinemeier \& Walter L. Friedrich. Monographs of the Danish Institute at Athens Volume 10. Athens: The Danish Institute at Athens. p 207-26.

Manning SW. 2010. Eruption of Thera/Santorini. In: Cline EH, editor. The Oxford Handbook of The Bronze Age Aegean (ca. 3000-1000 BC). New York: Oxford University Press. p 457-74.

Manning SW, Bronk Ramsey C. 2003. A Late Minoan III absolute chronology for the Aegean - combining archaeology with radiocarbon. In: Bietak M, editor. The Synchronisation of Civilisations in the Eastern Mediterranean in the Second Millennium BC (II). Proceedings of the SCIEM2000 EuroConference Haindorf, May 2001. Vienna: Österreichischen Akademie der Wissenschaften. p 111-33.

Manning SW, Bronk Ramsey C. 2009. The dating of the earlier Late Minoan IA period: a brief note. In: Warburton DA, editor. Time's Up! Dating the Minoan Eruption of Santorini. Acts of the Minoan Eruption Chronology Workshop, Sandbjerg November 2007 Initiated by Jan Heinemeier \& Walter L. Friedrich. Monographs of the Danish Institute at Athens Volume 10. Athens: The Danish Institute at Athens. p 227-45.

Manning SW, Kromer B. 2011 a. Radiocarbon dating archaeological samples in the Eastern Mediterranean, 1730-1480 BC: further exploring the atmospheric radiocarbon calibration record and the archaeological implications. Archaeometry 53:413-39.

Manning SW, Kromer B. 2011 b. Radiocarbon dating Iron Age Gordion and the Early Phrygian destruction in particular. In: Rose CB, Darbyshire G, editors. The New Chronology of Iron Age Gordion. Gordion Special Studies VI. Philadelphia: University of Pennsylvania Museum of Archaeology and Anthropology. p 123-53. (Note: a couple of typos/errors in the printed version of this paper are noted at http://cornell.academia.edu/SturtWManning/Papers/1167867).

Manning SW, Barbetti M, Kromer B, Kuniholm PI, Levin I, Newton MW, Reimer PJ. 2002. No systematic early bias to Mediterranean ${ }^{14} \mathrm{C}$ ages: radiocarbon measurements from tree-ring and air samples provide tight limits to age offsets. Radiocarbon 44(2):739-54.

Manning SW, Kromer B, Talamo S, Friedrich M, Kuniholm PI, Newton MW. 2005. Radiocarbon calibration in the east Mediterranean region. In: Levy TE, Higham T, editors. The Bible and Radiocarbon Dating Archaeology, Text and Science. London: Equinox. p 95-103.

Manning SW, Bronk Ramsey C, Kutschera W, Higham T, Kromer B, Steier P, Wild EM. 2006. Chronology for the Aegean Late Bronze Age 1700-1400 B.C. Science 312(5773):565-9.

Manning SW, Bronk Ramsey C, Kutschera W, Higham T, Kromer B, Steier P, Wild EM. 2009. Dating the Santorini/Thera eruption by radiocarbon: further discussion (AD 2006-2007). In: Manning SW, Bruce MJ, editors. Tree-Rings, Kings and Old World Archaeology and Environment: Papers Presented in Honor of Peter Ian Kuniholm. Oxford: Oxbow Books. p 299-316.

Manning SW, Kromer B, Bronk Ramsey C, Pearson CL, Talamo S, Trano N, Watkins JD. 2010. ${ }^{14} \mathrm{C}$ record and wiggle-match placement for the Anatolian (Gordion area) Juniper tree-ring chronology $\sim 1729$ to 751 cal $\mathrm{BC}$, and typical Aegean/Anatolian (growing season related) regional ${ }^{14} \mathrm{C}$ offset assessment. Radiocarbon 52(4):1571-97.

Manning SW, Kromer B, Dee M, Friedrich M, Higham T, Bronk Ramsey C. 2012. Radiocarbon calibration in the mid to later 14 th century $\mathrm{BC}$ and radiocarbon dating Tell el-Amarna, Egypt. In: Bronk Ramsey C, Shortland AJ, editors. Radiocarbon and the Chronologies of Egypt. Oxford: Oxbow Books. In press.

Merrillees RS. 2009. Chronological conundrums: Cypriot and Levantine imports from Thera. In: Warburton DA, editor. Time's Up! Dating the Minoan Eruption of Santorini. Acts of the Minoan Eruption Chronology Workshop, Sandbjerg November 2007 Initiated by Jan Heinemeier \& Walter L. Friedrich. Monographs of the Danish Institute at Athens Volume 10. Athens: The Danish Institute at Athens. p 247-51.

Muscheler R. 2009. ${ }^{14} \mathrm{C}$ and ${ }^{10} \mathrm{Be}$ around $1650 \mathrm{cal} \mathrm{BC}$. In: Warburton DA, editor. Time's Up! Dating the Minoan eruption of Santorini. Acts of the Minoan Eruption Chronology Workshop, Sandbjerg November 2007 Initiated by Jan Heinemeier \& Walter L. Friedrich. Monographs of the Danish Institute at Athens Volume 10. Athens: The Danish Institute at Athens. p 275-84.

Nelson DE, Vogel JS, Southon JR. 1990. Another suite of confusing radiocarbon dates for the destruction of $\mathrm{Ak}$ rotiri. In: Hardy DA, Renfrew AC, editors. Thera and the Aegean World III. Volume Three: Chronology. London: The Thera Foundation. p 197-206. 
Reimer PJ, Baillie MGL, Bard E, Bayliss A, Beck JW, Blackwell PG, Bronk Ramsey C, Buck CE, Burr GS, Edwards RL, Friedrich M, Grootes PM, Guilderson TP, Hajdas I, Heaton TJ, Hogg AG, Hughen KA, Kaiser KF, Kromer B, McCormac FG, Manning SW, Reimer RW, Richards DA, Southon JR, Talamo S, Turney CSM, van der Plicht J, Weyhenmeyer CE. 2009. IntCal09 and Marine09 radiocarbon age calibration curves, 0-50,000 years cal BP. Radiocarbon 51(4): $1111-50$.

Soter S. 2011. Radiocarbon anomalies form old $\mathrm{CO}_{2}$ in the soil and canopy air. Radiocarbon 53(1):55-69.

Spurr MS. 1986. Arable Cultivation in Roman Italy $c$. 200 B.C. - c.A.D. 100. Journal of Roman Studies Monographs No. 3. London: Society for the Promotion of Roman Studies.

Vinther BM, Clausen HB, Johnsen SJ, Rasmussen SO, Andersen KK, Buchardt SL, Dahl-Jensen D, Seierstad IK, Siggaard-Andersen ML, Steffensen JP, Svensson A, Olsen J, Heinemeier J. 2006. A synchronized dating of three Greenland ice cores throughout the Holocene. Journal of Geophysical Research 111: D13102, doi:10.1029/2005JD006921.

Vinther BM, Clausen HB, Johnsen SJ, Rasmussen SO, Steffensen JP, Andersen KK, Buchardt SL, DahlJensen D, Seierstad IK, Svensson AM, SiggaardAndersen M-L, Olsen J, Heinemeier J. 2008. Reply to comment by J. S. Denton and N. J. G. Pearce on "A synchronized dating of three Greenland ice cores throughout the Holocene." Journal of Geophysical Research 113:D12306, doi:10.1029/2007JD009083.

Warburton DA, editor. 2009. Time's Up! Dating the Minoan Eruption of Santorini. Acts of the Minoan Eruption Chronology Workshop, Sandbjerg November 2007 Initiated by Jan Heinemeier \& Walter L. Friedrich. Monographs of the Danish Institute at Athens Volume 10. Athens: The Danish Institute at Athens.

Ward GK, Wilson SR. 1978. Procedures for comparing and combining radiocarbon age determinations-a critique. Archaeometry 20(1):19-31.

Warren P. 1984. Absolute dating of the Bronze Age eruption of Thera (Santorini). Nature 308(5959):492-3.

Warren P. 1985. Minoan pottery from Egyptian sites. Classical Review 35:147-51.

Warren P. 1987. Absolute dating of the Aegean Late Bronze Age. Archaeometry 29:205-11.

Warren P. 2009. The date of the Late Bronze Age eruption of Santorini. In: Warburton DA, editor. Time's Up! Dating the Minoan Eruption of Santorini. Acts of the
Minoan Eruption Chronology Workshop, Sandbjerg November 2007 Initiated by Jan Heinemeier \& Walter L. Friedrich. Monographs of the Danish Institute at Athens Volume 10. Athens: The Danish Institute at Athens. p 181-6.

Warren PM. 2010. The absolute chronology of the Aegean circa 2000 B.C. -1400 B.C. A summary. In: Müller W, editor. Die Bedeutung der minoischen und mykenischen Glyptik. VI. Internationales Siegel-Symposium aus Anlass des 50 jährigen Bestehens des CMS Marburg, 9-12 October 2008. CMS Beiheft 8. Mainz: Philipp von Zabern. p 383-94.

Warren P, Hankey V. 1989. Aegean Bronze Age Chronology. Bristol: Bristol Classical Press.

Wiener MH. 2003. Time out: the current impasse in Bronze Age archaeological dating. In: Foster KP, Laffineur R, editors. Metron: Measuring the Aegean Bronze Age. Aegaeum 24. Liège: Université de Liège, Service d'histoire de l'art et d'archéologie de la Grèce antique and University of Texas, Program in Aegean Scripts and Prehistory. p 363-99.

Wiener MH. 2006. Chronology going forward (with a query about 1525/4 B.C.). In: Czerny E, Hein I, Hunger H, Melman D, Schwab A, editors. Timelines: Studies in Honor of Manfred Bietak. Leuven: Peeters. p 317-28.

Wiener MH. 2009a. The state of the debate about the date of the Theran eruption. In: Warburton DA, editor. Time's Up! Dating the Minoan Eruption of Santorini. Acts of the Minoan Eruption Chronology Workshop, Sandbjerg November 2007 Initiated by Jan Heinemeier \& Walter L. Friedrich. Monographs of the Danish Institute at Athens Volume 10. Athens: The Danish Institute at Athens. p 197-206.

Wiener MH. 2009b. Cold fusion: the uneasy alliance of history and science. In: Manning SW, Bruce MJ, editors. Tree-Rings, Kings and Old World Archaeology and Environment: Papers Presented in Honor of Peter Ian Kuniholm. Oxford: Oxbow Books. p 277-92, 317-27, 329-30.

Wiener MH. 2010. A point in time. In: Krzyszkowska O, editor. Cretan Offerings: Studies in Honour of Peter Warren. London: The British School at Athens. p 36794.

Wild EM, Gauß W, Forstenpointner G, Lindblom M, Smetana R, Steier P, Thanheiser U, Weninger F. 2010. ${ }^{14} \mathrm{C}$ dating of the Early to Late Bronze Age stratigraphic sequence of Aegina Kolonna, Greece. $\mathrm{Nu}$ clear Instruments and Methods in Physics Research B 268(7-8):1013-21. 